San Jose State University

SJSU ScholarWorks

Master's Theses

Master's Theses and Graduate Research

2006

\title{
The moderating role of optimism as related to work resources and work engagement
}

Matthew M. Jezzi

San Jose State University

Follow this and additional works at: https://scholarworks.sjsu.edu/etd_theses

\section{Recommended Citation}

Jezzi, Matthew M., "The moderating role of optimism as related to work resources and work engagement" (2006). Master's Theses. 2956.

DOI: https://doi.org/10.31979/etd.wxbt-b3zk

https://scholarworks.sjsu.edu/etd_theses/2956

This Thesis is brought to you for free and open access by the Master's Theses and Graduate Research at SJSU ScholarWorks. It has been accepted for inclusion in Master's Theses by an authorized administrator of SJSU ScholarWorks. For more information, please contact scholarworks@sjsu.edu. 


\title{
THE MODERATING ROLE OF OPTIMISM AS RELATED TO WORK RESOURCES AND WORK ENGAGEMENT
}

\author{
A Thesis \\ Presented to \\ The Faculty of the Department of Psychology \\ San Jose State University \\ In Partial Fulfillment \\ Of the Requirements for the Degree \\ Master of Science \\ by \\ Matthew M. Jezzi
}

August 2006 
UMI Number: 1438571

Copyright 2006 by

Jezzi, Matthew M.

All rights reserved.

\section{INFORMATION TO USERS}

The quality of this reproduction is dependent upon the quality of the copy submitted. Broken or indistinct print, colored or poor quality illustrations and photographs, print bleed-through, substandard margins, and improper alignment can adversely affect reproduction.

In the unlikely event that the author did not send a complete manuscript and there are missing pages, these will be noted. Also, if unauthorized copyright material had to be removed, a note will indicate the deletion.

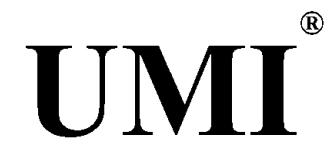

UMI Microform 1438571

Copyright 2007 by ProQuest Information and Learning Company.

All rights reserved. This microform edition is protected against unauthorized copying under Title 17, United States Code.

ProQuest Information and Learning Company

300 North Zeeb Road

P.O. Box 1346

Ann Arbor, MI 48106-1346 
(C) 2006

Matthew M. Jezzi

ALL RIGHTS RESERVED 
APPROVED FOR THE DEPARTMENT OF PSYCHOLOGY
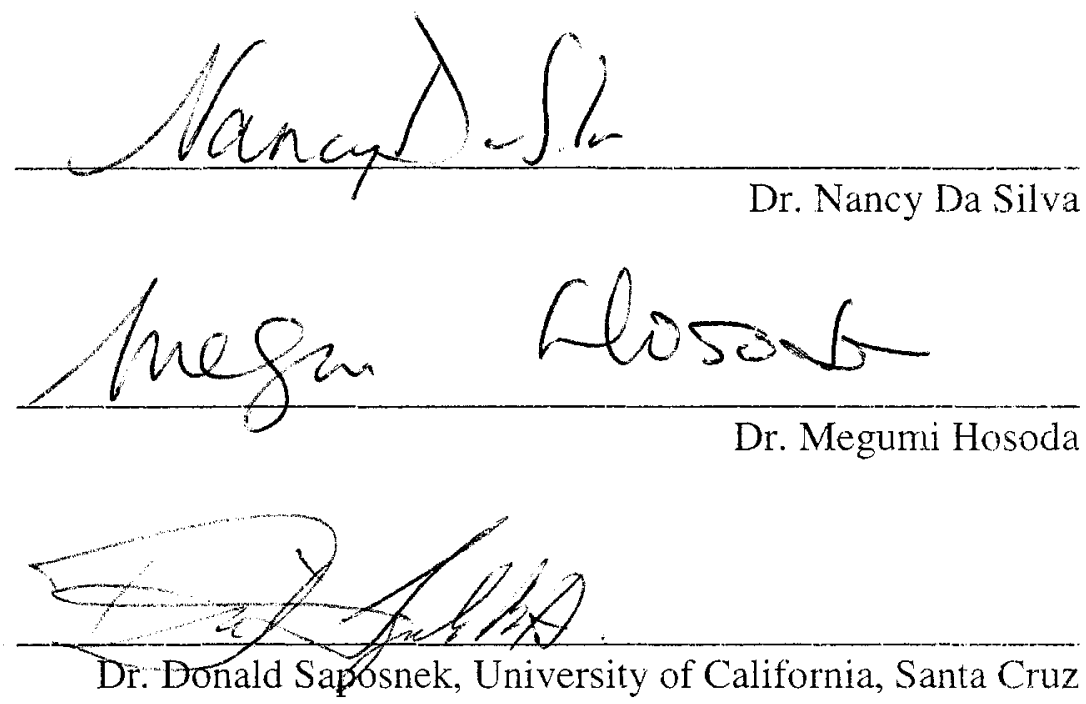

\section{APPROVED FOR THE UNIVERSITY}

Fhent Whllearmon $07 / 13 / 06$ 


\title{
ABSTRACT \\ THE MODERATING ROLE OF OPTIMISM AS RELATED TO WORK RESOURCES AND WORK ENGAGEMENT
}

\author{
by Matthew M. Jezzi
}

A total of 216 employed participants from two samples were surveyed in a study of work engagement, defined as vigor, dedication, and absorption. The study focused on two primary objectives: 1) it used an application of the Job Demands-Resources Model which focused on four work resources and two work attitudes to predict work engagement; 2) it evaluated the moderating role of optimism with work resources and work engagement.

The results revealed partial support for the prediction of engagement with work resources, job involvement, and optimism. Affective commitment did not significantly predict engagement. The results also revealed a small moderating role of optimism with work resources, vigor, and absorption, such that the relationships of work resources with vigor and absorption are stronger for individuals high in optimism than for those low in optimism. The hypotheses and results are discussed within the framework of the positive psychology perspective. 


\section{Acknowledgements}

I would like to thank my psychology thesis readers for their dedication and support throughout the thesis process. Megumi Hosoda provided essential support with my hypothesis generation and statistical interpretation. The quality of my thesis surely benefited from her eye for detail, along with her deft critique of statistical, theoretical, and stylistic issues. I would like to thank Don Saposnek for introducing me to the study of positive psychology. Dr. Saposnek encouraged me to study the science and practice of psychology in non-traditional, meaningful ways. I would like to give special recognition to my first reader, Nancy Da Silva. Throughout the thesis process, Dr. Da Silva demonstrated unyielding dedication and patience, from which I have benefited tremendously. Thank you Nancy for challenging me to think and work beyond what I thought were my capabilities.

I would also like to thank all of my participants. This thesis would not have been possible without the participation of employees and students. The cooperation of faculty and managers was very helpful.

I would like to thank my friends and family for all the support they have provided me. I would like to thank my parents for their unconditional support and encouragement. I would also like to thank my brothers for inspiring me with all of their hard work and always making me laugh.

Finally, thanks to my Industrial/Organizational Psychology classmates. You have been my friends, constructive critics, and wonderful resources. I will truly miss our time together. 


\section{TABLE OF CONTENTS}

List of Tables vii

Introduction 1

Work Engagement 2

Personal Engagement 3

Job Engagement $\quad 5$

Employee Engagement $\quad 8$

Self-Engagement $\quad 8$

Work Engagement: Similarities and Differences among Perspectives 10

Related Constructs $\quad 13$

Work Resources and Engagement 15

Affective Commitment and Job Involvement 19

Personal Characteristics and Work Engagement 21

$\begin{array}{ll}\text { Optimism } & 22\end{array}$

$\begin{array}{ll}\text { Method } & 25\end{array}$

Participants 25

Participants from the non-profit organization 25

Student participant information $\quad 25$

$\begin{array}{ll}\text { Procedure } & 26\end{array}$

Procedure for non-profit sample $\quad 26$

Procedure for student sample $\quad 26$

$\begin{array}{ll}\text { Measures } & 27\end{array}$

Analyses $\quad 30$

Results $\quad 32$

Factor Analyses $\quad 32$

Descriptive Statistics 44

Correlations for Vigor $\quad 45$

Correlations for Dedication $\quad 45$

$\begin{array}{ll}\text { Correlations for Absorption } & 48\end{array}$

Correlations for Demographic Variables $\quad 49$

Hierarchical Moderated Regression Analyses $\quad 49$

Hierarchical Moderated Regression for Vigor $\quad 49$

Hierarchical Moderated Regression for Dedication $\quad 55$

Hierarchical Moderated Regression for Absorption $\quad 57$

$\begin{array}{ll}\text { Discussion } & 63\end{array}$

Strengths and Limitations $\quad 64$

Implications for Research and Practice $\quad 66$

References

71

$\begin{array}{ll}\text { Footnotes } & 75 \\ & 71\end{array}$

Appendix: Survey Items $\quad 76$ 


\section{LIST OF TABLES}

Table 1. Principal components analysis of work engagement, p. 33 with oblimin rotation.

Table 2. Exploratory principal components analysis of work resources, p. 35 with oblimin rotation.

Table 3. Forced principal components analysis of work resources, p. 38 with oblimin rotation (see Appendix for items).

Table 4. Forced principal components analysis of job involvement, $\quad$ p. 41 with oblimin rotation.

Table 5. Forced principal components analysis of affective commitment, p. 42 with oblimin rotation.

Table 6. Forced principal components analysis of optimism, with oblimin rotation.

Table 7. Descriptive statistics and correlations for the entire sample p. 46 $(\mathrm{N}=206)$.

Table 8. Regression analysis predicting vigor $(\mathrm{N}=209)$ p. 51

Table 9. Linear regressions for the interaction of optimism p. 53 with vigor $(\mathrm{N}=214)$.

Table 10. Regression analysis predicting dedication $(\mathrm{N}=206) . \quad$ p. 56

$\begin{array}{ll}\text { Table 11. Regression analysis predicting absorption }(\mathrm{N}=208) . & \text { p. } 58\end{array}$

$\begin{array}{ll}\text { Table 12. Linear regressions for the interaction of optimism } & \text { p. } 60\end{array}$ with absorption $(\mathrm{N}=214)$. 
Introduction

In the last few years, psychological research has begun to focus on studying individuals from a positive rather than negative perspective (Seligman \& Csikszentmihalyi, 2000). Seligman and Csikszentmihalyi argued that the focus on a "positive psychology" is needed to encompass all aspects of psychology. This emerging psychology focuses on building positive human qualities rather than exclusively studying the repair of human maladaptive behaviors. In addition, Seligman and Csikszentmihalyi described the second half of the twentieth century to be an era in which psychology focused exclusively on healing maladaptive behaviors and pathology. The focus on maladaptive behaviors was largely the result of economic and political factors that emerged after World War II. Conversely, the new perspective has included the "optimal functioning of individuals" and "identifying and nurturing high talent" as its missions. Incorporating a positive perspective, this thesis evaluated aspects of work behavior traditionally studied under stress research. For example, recent research has proposed a "positive antipode" of burnout called work engagement (Maslach, Schaufeli, \& Leiter, 2001). In this thesis, work engagement was defined work engagement a brief review of the related literature was provided. Research on related subjects such as burnout has often focused on correlates and moderators that act as buffering effects (Riolli \& Savicki, 2003; Duquette, Kerouac, Sandhu, Ducharme, \& Saulnier, 1995; Collins, 1996). This thesis evaluated the role of correlates and moderators, as related to work engagement. Furthermore, this thesis evaluated the relationships of different work resources with work engagement, which have not been studied in previous research. In 
addition, this thesis defined different work attitudes, and described their theoretical connection to work engagement. The work resources examined in this study expand on previous research that evaluated the relationship of work resources with work engagement and affective commitment (Schaufeli \& Bakker, 2004). Seligman and Csikszentmihalyi (2000) noted that the study of positive personal characteristics, such as optimism, fit with the under-emphasized missions of psychology. The final purpose of this thesis was to evaluate the interaction of a personal characteristic with work engagement and work resources. In sum, this thesis evaluated work engagement, its relationship with work resources, job involvement, and affective commitment, and the moderating role of optimism.

\section{Work Engagement}

In this thesis, work engagement was described from four separate but related perspectives (Ford \& Poms, 2005). These perspectives were organized by the construct names provided in the original respective research as personal engagement (Kahn, 1990); work engagement (Schaufeli \& Bakker, 2004); employee engagement (Harter, Hayes, \& Schmidt, 2002); and self-engagement (Britt, 1999). With the exception of these different perspectives, this thesis referred to the engagement construct as work engagement. The intent of this thesis was to focus on one's experience at work rather than on a specific person, employee, or job. The similarity of this conceptualization with Schaufeli \& Bakker's (2004) study was also discussed. More over, this thesis provided a brief review of the literature that supports each perspective. Following these reviews, this thesis discussed the relevance of each perspective to this thesis. 


\section{Personal Engagement}

In the first perspective, Kahn (1990) defined engagement as "the harnessing of organization members' selves to their work roles," where people "employ and express themselves physically, cognitively, and emotionally during role performances" (p. 694). When individuals are engaged, they report being "attentive, absorbed, or involved in their work" (p. 698).

According to Kahn's qualitative study, three conditions influence an individual's personal engagement: meaningfulness, safety, and availability. Experienced meaningfulness is a feeling that one is valued for his or her work. In addition, one feels that his or her job is important and challenging. The degree of meaningfulness experienced is influenced by task interactions, work roles and work interactions, much like Hackman and Oldham's (1980) job characteristics. Jobs are more meaningful if they are challenging, include skill variety, and facilitate a sense of autonomy. Additionally, jobs that offer work roles which fit with how one wants to be viewed will lead to an experience of meaningfulness (Kahn, 1990). Lastly, jobs that include interpersonal interactions that promote a sense of dignity and professionalism will lead to greater meaningfulness (Kahn, 1990).

Safety is experienced when individuals can openly express themselves in their work roles. Furthermore, safety is experienced when expressing oneself will not jeopardize his or her ability to keep his or her job, maintain good reputations, and continue to feel a sense of self-worth. The amount of safety one experiences is influenced by interpersonal and organizational variables. These variables include 1) the 
relationships one has with his or her coworkers, supervisors, and subordinates, 2) the biases that occur within and between different work groups, 3) the procedures and interactions taken by management, and 4) the cultural norms of the organization (Kahn, 1990). For example, if coworkers are not supportive, the employee will not feel safe to openly express his or her work-related emotions and ideas.

In addition to meaningfulness and safety, an individual must feel that he or she has enough mental, social, emotional, and physical resources available to engage himself or herself in a work role (Kahn, 1990). This sense of availability might vary at different times and is influenced by the amount of physical and emotional energy one has (Kahn, 1990). In addition, a sense of availability is influenced by the different work/life demands with which one must cope (Kahn, 1990).

In conclusion, Kahn (1990) provided a good theoretical framework for studying personal engagement. The relationships found between each condition (i.e., meaningfulness, safety, availability) and personal engagement provided support for the study of antecedents with personal engagement.

May, Gilson, and Harter (2004) provided empirical support for personal engagement by evaluating the antecedents and mediating effect of the three psychological conditions on engagement. Not only did they find that the three conditions were positively related to engagement, they found that these conditions mediated the relationships of several other antecedents with engagement. More specifically, meaningfulness positively mediated the relationship of job enrichment and work role fit with engagement. May's et al. study demonstrated several other relationships. First, 
supportive coworker relations and supervisor support were positively related to psychological safety. Second, self-consciousness was negatively related to safety. Third, adherence to coworker norms was negatively related to safety, which partially mediated their relation to engagement. May's et al. analyses also revealed that availability was positively related to resources and negatively related to participation in outside activities. Lastly, these researchers found that resources and self-consciousness had direct positive relations with engagement. These findings have provided empirical support for studying the antecedents of personal engagement. The findings have provided additional support for the role of personal engagement as a mediator of organizational outcomes. Finally, these findings have also supported the use of Kahn's theoretical framework for studying work engagement.

Job Engagement

A second perspective described that job engagement is composed of three dimensions (i.e., vigor, dedication, and absorption), which Maslach et al. (2001) originally described as the opposites of the burnout dimensions, namely, emotional exhaustion, cynicism, and reduced professional efficacy. Following this perspective, engagement has been defined as "a positive, fulfilling, work-related state of mind that is characterized by vigor, dedication, and absorption" (Schaufeli \& Bakker, 2004, p.295). Specifically, "engagement refers to a persistent and pervasive affective-cognitive state that is not focused on any particular object, event, individual, or behavior" (Schaufeli \& Bakker, 2004, p.295). Vigor has been described as a state where one experiences a high degree of energy, a strong work ethic, and an ability to persevere when confronted with 
challenging work (Schaufeli \& Bakker, 2004). Individuals who experience dedication are very involved in their work. In addition, dedicated individuals have an enthusiastic attitude and report being inspired and proud of their work. Individuals who experience dedication also perceive their work to be significant. Furthermore, they describe difficulties as challenges rather than strains. Absorption in work entails being fully immersed in work and feeling happy about one's work roles. Individuals who are absorbed in their work perceive time to pass quickly and find it difficult to separate themselves from work tasks (Schaufeli \& Bakker, 2004).

Research evaluating job engagement from this perspective has not been vast. Much of this research has studied the relationship of work resources with the dimensions of work engagement, using the job demands-resources model (JD-R). This model states that all jobs involve demands and resources (Demerouti, Nachreiner, Bakker, \& Schaufeli, 2001).

Several studies have researched work resources within the context of the JD-R model. One empirical study measured the relationship of work-home interference with work engagement and burnout (Montgomery, Peeters, Schaufeli, \& Den Ouden, 2003). Montgomery et al. (2003) found that negative interference from home-to-work (i.e., when negative experiences at home interfere with one's work life) was negatively related to vigor. In addition, positive work-to-home interference (i.e., when positive experiences at work positively influence one's home life) was positively related to dedication. The resource (i.e., social support from colleagues) was positively related to both vigor and dedication. The absorption dimension was not measured in Mongomery et al.'s study. 
The relationship of work resources and demands with engagement was further tested in a multi-sample Dutch study (Schaufeli \& Bakker, 2004). These researchers found that the work resources of coaching and feedback were positively related to vigor, dedication, and absorption. Similar to previous research, Schaufeli and Bakker studied the resource social support. They found social support to be positively related to vigor and dedication. Schaufeli and Bakker's study demonstrated that work engagement mediated the relationship between work resources and turnover.

Both Demerouti et al.'s (2001) and Schaufeli and Bakker's (2004) studies have had direct implications for this thesis. First, they have provided support for the study of work engagement as a multi-dimensional construct. Second, Schaufeli and Bakker's study has provided support for using the JD-R model to study other work resources and antecedents with vigor, dedication, and absorption.

Sonnentag (2003) studied work engagement from the work engagement perspective. However, her research described work engagement as a global term, which combined the items of the three dimensions (i.e., vigor, dedication, absorption). Sonnentag found that recovery (i.e., periods of rest from work such as vacations) had a positive effect on work engagement and proactive behaviors. In addition, the author found that work engagement mediated the relationship between recovery and proactive behaviors. Although Sonnentag did not evaluate work engagement as a multidimensional construct, her study provided support for work engagement as a positive experience, which results in positive outcomes for organizations. 


\section{Employee Engagement}

In the third perspective, employee engagement has been defined as "the individual's involvement and satisfaction with as well as enthusiasm for work" (Harter, Hayes, \& Schmidt, 2002, p.269). Harter et al. found that employee engagement was positively correlated with several predicted outcomes: customer satisfaction, productivity, profit, employee retention, and employee safety. These researchers also found that these outcomes did not substantially vary across 36 organizations. This finding provided support for the generalizability of employee engagement across different industries.

Research has demonstrated a negative relationship between span of control (i.e., the number of direct reports to a supervisor) and work engagement (Cathcart, Jeska, Karnas, Miller, Pechacek, \& Rheault, 2004). These authors found that this relationship was not moderated by demographic variables such as tenure, work status, and job type. Cathcart et al.'s study demonstrated how a stressor can have a negative relationship with employee engagement. This was the opposite of the relationship that stressors have had with burnout (Lee \& Ashforth, 1996). Hence, when stressors increase engagement decreases; conversely, when stressors increase burnout increases. Similar results were found in Bakker et al.'s (2003) study where work resources were negatively related to burnout and positively related to work engagement.

\section{Self-Engagement}

The fourth perspective has defined self-engagement as the degree to which one "identifies with" and "feels responsible and committed" to his or her work experience (Britt, 1999, p.698). This research has provided evidence that self-engagement 
"magnifies" the relationship that different work attitudes and stressors will have with an individual's psychological health (Britt, 1999). For example, Britt (1999) found that the negative relationship between work stress and health was stronger for highly-engaged soldiers than for disengaged soldiers. The research also concluded that the relationship between perceptions of success at work and psychological health was stronger when soldiers were high in self-engagement than when they were low in self-engagement (Britt, 1999). Britt (2003) extended this research to a non-work context. He found that self-engagement predicted self-reported voting behavior among university students. Britt's (1999) study implied that high self-engagement might not always be beneficial. Although this exception is noteworthy, it is important to emphasize that the definition used in this perspective contains terms like responsibility, commitment, and identification, which could have been the source of these divergent relationships. This thesis described differences between the definition of self-engagement and the other three perspectives in a later section.

This research perspective has also evaluated the role of personal characteristics with self-engagement. Britt, Bartone, and Adler (2001) found a relationship between self engagement and the personality variable hardiness. In this study, finding meaning in work, a variable from the hardiness literature (not personal engagement), was positively related to hardiness. Furthermore, hardiness was positively related to other relevant variables: Hardiness was related to self-engagement, and it was related to perceived benefits as a result of participation in a military operation. Britt et al.'s study has 
provided support for the relationship of a positive personal characteristic with selfengagement.

In addition to studying the relationships that self-engagement has with other positive variables, research has also evaluated its role with stress. Britt and Bliese's (2003) study demonstrated that self-engagement buffered the stressor-strain relationship. In this study, the stressors (i.e., work stressors, lack of sleep, and family stressors) were measured in relation to reported distress. More specifically, the researchers found that when stressors were low, the level of engagement did not influence the stressor-strain relationship. However, when stressors were high, individuals with high engagement reported lower distress than individuals with low engagement.

Work Engagement: Similarities and Differences among Perspectives

Although the four different definitions of engagement have been presented as discrete perspectives, they are related, especially via Kahn's (1990) perspective. Kahn's qualitative study has offered a theoretically rich conceptualization of engagement, which has served as a good theoretical comparison to burnout. In addition, Kahn's description of the relationship between the three conditions and engagement has complimented Shaufeli and Bakker's (2004) explanation of the Job Demands-Resources Model (JD-R). However, Kahn's operational definition of engagement is still vague and has incorporated terms such as involvement, which has confused the construct with other theoretical constructs (i.e., job involvement).

As described in the second perspective, work engagement is composed of vigor, dedication, and absorption, which are negative correlates of the multi-dimensional 
construct of burnout (Schaufeli et al., 2002; Shaufeli \& Bakker, 2004). The definition described by Schaufeli et al. (2002) and Schaufeli and Bakker (2004) have provided evidence of work engagement as a cognitive-affective state that is pervasive and distinct from burnout. This thesis supported this distinction from earlier research because of the theoretical support offered by Kahn's (1990) study and Schaufeli and Bakker's (2003) study. Furthermore, the empirical support described from four perspectives has provided support for work engagement as a cognitive, emotional, and/or physical state (Maslach et al., 2001).

Other similarities among the four perspectives can be described. For example, the vigor and dedication dimensions of Shaufeli et al's (2002) definition resembled the physical and emotional aspects of Kahn's conceptualization. Similar definitions between Kahn's physical component and Schaufeli et al.'s absorption dimension can also be described. Ford and Poms (2005) corroborated these similarities. Using Schaufeli et al.'s scale, they provided justification for using availability and meaningfulness as antecedents of engagement. This has provided an important theoretical link between the personal engagement and job engagement perspectives. Furthermore, Ford and Pom's study compared three of these divergent perspectives for the purpose of describing work engagement. The other engagement perspectives can also be reviewed for the purpose of identifying theoretical and empirical similarities.

Research has provided support for the link between Kahn's conceptualization and the employee engagement research (Harter et al. 2002). Harter et al. (2002) noted a similarity between their employee engagement definition and Kahn's definition by 
describing emotional attachment and mental concentration as qualities of work engagement. Furthermore, May, Gilson, and Harter (2002) found meaningfulness and availability to be important predictors of employee engagement. Although Harter et al.'s (2002) employee engagement definition is similar to Kahn's personal engagement and Schaufeli and Bakker's work engagement dimensions, the employee engagement researchers operationalized their construct as satisfaction and involvement rather than emotions, pride, and absorption. This thesis argued that the employee engagement perspective is not adequate to use alone. However, the theoretical similarity of employee engagement to the other engagement perspectives provides support for its inclusion in future work engagement research.

Lastly, Britt's (1999) self-engagement perspective can be compared with the other engagement perspectives. For example, self-engagement is similar to Kahn's (1990) personal engagement. Although the self-engagement definition included identification, responsibility and commitment, the inclusion of self-engagement compliments Kahn's (1990) personal engagement perspective (Britt \& Bliese, 2003). Even though selfengagement is defined differently than personal engagement, the authors of both perspectives describe the experience of engagement similarly. In addition, Kahn's (1990) experienced meaningfulness antecedent is comparable to Britt et al.'s (2001) finding meaning in a work role variable, which indicates similarities in the types of variables the two perspectives are studying. In conclusion, this thesis argued that research from the self-engagement perspective should be included in future work engagement research. However, the "identification with" and "commitment to" aspects of the definition should 
be omitted from future research about work engagement in order to distinguish it from job involvement and organizational commitment (Rothbard, 2001).

In summary, this thesis used Shaufeli et al.'s (2004) definition of work engagement, which includes the dimensions of vigor, dedication, and absorption. As argued in this thesis, this definition is supported by Kahn's (1990) conceptualization with further empirical support provided by the employee engagement and self-engagement perspectives. Hence, the remainder of this thesis discussed the work engagement construct as the dimensions of vigor, dedication, and absorption.

\section{Related Constructs}

Although work engagement is a relatively new construct, other researchers have studied similar constructs (Kanungo, 1982; Csikszentmihalyi, 1990). These constructs are noteworthy because their definitions have sometimes shared similar terms with those mentioned above. However, they are distinct constructs so similarities and differences of their definitions were noted. More specifically, constructs that have been related to work engagement are flow (Csikszentmihalyi, 1990) and job involvement (Lawler \& Hall, 1970; Lodahl \& Kejner, 1965; Kanungo, 1982; Brown, 1996).

Some of the related constructs have been defined similarly to work engagement. However, in some cases these related constructs were theoretically less encompassing than the construct of work engagement. In other cases, they related to only one of the engagement dimensions described in this thesis. Previous research has distinguished job involvement and flow from job engagement (May et al., 2004). 
In the case of job involvement, Ford and Poms (2005) provided evidence for work engagement as a correlated construct. These researchers found that the three dimensions of work engagement (especially absorption) positively related to involvement. Although job involvement research has evaluated broader work behaviors than a specific dimension of work engagement, the overall theoretical foundation of job involvement has been unrelated to work engagement (Lawler \& Hall, 1970, Lodahl \& Kejner, 1965). That is, job involvement was described as an employee's identification with their job. The individual reports feeling responsible for completing their job, and their self-esteem is affected by their effectiveness in completing job-related tasks (Britt, 1999; Lodahl \& Kejner, 1965). The relationship of job involvement with work engagement was addressed in further detail in a later section.

Flow has been defined as "the state in which people are so involved in an activity that nothing else seems to matter; the experience itself is so enjoyable that people will do it even at great cost, for the sheer sake of doing it" (Csikszentmihalyi, 1990, p. 4). This construct is similar to absorption. However, unlike absorption, flow includes the willingness to endure losses to partake in the activity. In addition, this construct does not include the physical or emotional components (i.e., vigor or dedication) that the work engagement literature evaluates. Previous research has not evaluated flow as a correlate, antecedent, or outcome of work engagement. However, because the existing operational definitions of flow are vague, it was not evaluated further in this thesis. 


\section{Work Resources and Engagement}

According to the Job Demands-Resources (JD-R) Model, all job characteristics can be categorized as having job demands and job resources (Demerouti et al., 2001).

Job demands refer to those physical, social, or organizational aspects of the job that require sustained physical or mental effort and are therefore associated with certain physiological and psychological costs (e.g. exhaustion)... Job resources refer to those physical, psychological, social, or organizational aspects of the job that may do any of the following: (a) be functional in achieving work goals; (b) reduce job demands at the associated physiological costs; and (c) stimulate personal growth and development. (p. 501)

Common resources that have been studied in the burnout and engagement literature are social support (i.e., from supervisors, coworkers, friends, and family), autonomy, performance feedback, financial rewards, supervisor coaching, and opportunities for professional development (Riolli \& Savicki, 2003; Bakker et al., 2003; Schaufeli \& Bakker, 2004). The JD-R model proposes that burnout develops via two processes. In the first process, high job demands tax an individual's physiological and psychological strategies to manage their performance. The over-taxing of these strategies leads to burnout. In the second process, a lack of job resources makes coping with job demands more difficult and increases withdrawal behaviors. Over time, this situation leads to reduced motivation and disengagement from work. Through this model, it has been argued that the interaction of job demands and resources are the most important predictors in the development of burnout (Demerouti et al., 2001). Bakker, Demerouti, and Shaufeli (2003) found support for this model by examining the influence of job demands and job resources on absenteeism. Bakker et al. found that the first process of the model demonstrated a "health impairment process" where job demands led to 
burnout. This burnout, in turn, led to an increase in absence duration. The second process of the model was described as "motivational" in nature. Bakker et al. suggest that employees with high work resources might be more motivated to do their job. Such motivation leads to greater organizational commitment and lower absenteeism. Support was found for a positive relationship between job resources and affective and continuance commitment; affective and continuance commitment were negatively related with absence frequency (Bakker et al., 2003). Therefore, the results of the study provided support for both processes of the JD-R model.

This thesis addressed the second process associated with the JD-R Model. According to the model, "the process links job resources via engagement with organizational outcomes" (Schaufeli \& Bakker, 2004, p. 298). Job resources can also be intrinsically or extrinsically motivating. Because of their relationship with learning, development, and personal growth, job resources can be intrinsically rewarding (Schaufeli \& Bakker, 2004). In addition, job resources can act as an external reinforcer, because they aid in the achievement of work goals. Regardless of the nature of motivation, the model states that "the outcome is positive and engagement - a fulfilling, positive work-related state of mind - is likely to occur" (p. 298). Schaufeli and Bakker (2004) found support for this model by evaluating the following work resources: feedback, social support, and supervisory coaching. Schaufeli and Bakker found that these resources predicted the three dimensions of work engagement (i.e., vigor, dedication, and absorption), which mediated the relationship between work resources and turnover intentions. These authors recommended future research into other resources 
"more distal from job demands (e.g., career perspective, skill development, and learning opportunities)" (p. 311). This thesis followed Schaufeli and Bakker's recommendation by studying resources related to job learning, skill development, and career development as predictors of work engagement. Four work resources that have not been studied with work engagement are coworker support for development, supervisor support for development, nonwork support for development (i.e., support from friends and family), and availability of learning and development policies. These resources were studied in relation to the three work engagement dimensions.

Research has already demonstrated that social support from colleagues is positively related to both vigor and dedication (Montgomery et al., 2003; Bakker \& Schaufeli, 2003). This thesis argued that when coworkers are supportive of one's skill/professional development, he or she will also be likely to experience vigor, dedication, and absorption in his or her work. In addition, the support of one's supervisor is important for an employee to feel engaged in his or her work. Hence, this thesis hypothesized that coworker support for development is predictive of vigor, dedication, and absorption.

According to Kahn's framework, supportive interpersonal relationships and interactions influence the degree of meaningfulness and safety an individual will experience. Because research has shown these conditions to be predictive of work engagement, this thesis hypothesized that supervisor support for development is predictive of vigor, dedication, and absorption (May et al., 2004). In addition, this thesis 
predicted that supervisor support for development has a positive relationship with vigor, dedication, and absorption.

Ford and Poms' (2005) research demonstrated that a sense of availability of resources was predictive of work engagement. This study expanded on the availability construct to include the availability of development resources. It is argued that the availability of development resources should be predictive of vigor, dedication, and absorption.

When family members and/or trusted friends are supportive of one developing his or her career, one should feel more engaged in one's work. Rothbard (2001) found that family positive affect was positively related to work absorption, where work engagement was defined as attention and absorption. Hence, this thesis argued that nonwork support for development was positively related to, and predictive of, vigor, dedication, and absorption.

In addition to the relationships stated above, research has demonstrated that organizational demographic variables are predictive of work engagement (Cathcart, 2003). Hence, this thesis predicted that the four work resources are predictive of vigor, dedication, and absorption after controlling for the demographic variables of sample type, sex, tenure, and age.

Hypothesis 1: Work resources (coworker support for development, supervisor support for development, resource availability for development, and nonwork support for development) predict vigor after controlling for sample type, sex, tenure, and age. 
Hypothesis 2: Work resources (coworker support for development, supervisor support for development, resource availability for development, and nonwork support for development) predict dedication after controlling for sample type, sex, tenure, and age.

Hypothesis 3: Work resources (coworker support for development, supervisor support for development, resource availability for development, and nonwork support for development) predict absorption after controlling for sample type, sex, tenure, and age.

\section{Affective Commitment and Job Involvement}

Hobfoll and Freedy (1990) indicated that resource loss and burnout are related to behavioral and attitudinal outcomes. Research has identified these outcomes as turnover intentions, reduced preventive coping, reduced control coping, reduced positive attitudes toward workplace climate, reduced organization commitment, and lower job involvement and satisfaction (Kahill, 1988; Lee \& Ashforth, 1996). Other research has extended the study of these relationships by evaluating these variables as outcomes of work engagement. For example, Bakker et al. (2003) found support for the hypothesis that work resources would predict affective and continuance commitment; support was not found for the hypothesized relationship between work resources and normative commitment. Because work resources help with accomplishing goals and promote a feeling of success, Bakker et al. theorized that work resources lead to the enhancement of one's commitment to the organization. Ford and Poms (2005) found that the job satisfaction predicted the three dimensions of work engagement. In addition, Ford and 
Poms found job involvement to be related to the three dimensions of work engagement. Lastly, a study showed job attitudes, such as job satisfaction and job involvement, to be correlates of affective commitment and turnover intentions (Meyer, Stanley, Herscovitch, \& Topolnytsky, 2002). There is no research that has studied affective commitment as a predictor or outcome of work engagement. Because research has shown both a correlation between work resources and work engagement as well as a correlation between work resources and affective commitment, there are grounds for thinking that affective commitment is related to work engagement. Furthermore, because these variables (i.e., job involvement, job satisfaction, and life satisfaction) have an "affective tone," they are considered to be correlates of affective commitment (Meyer et al., 2002). The definitions of job involvement and affective commitment, unlike job satisfaction, have been found to share terms similar to the engagement perspectives described earlier. This thesis was designed to differentiate them as positively related but discrete constructs. Hence, this thesis put forth the hypothesis that affective commitment and job involvement predict the three dimensions of work engagement.

Hypothesis 4: Affective commitment predicts vigor after controlling for sample type, sex, tenure, and age.

Hypothesis 5: Affective commitment predicts dedication after controlling for sample type, sex, tenure, and age.

Hypothesis 6: Affective commitment predicts absorption after controlling for sample type, sex, tenure, and age. 
Hypothesis 7: Job involvement predicts vigor after controlling for sample type, sex, tenure, and age.

Hypothesis 8: Job involvement predicts dedication after controlling for sample type, sex, tenure, and age.

Hypothesis 9: Job involvement predicts absorption after controlling for sample type, sex, tenure, and age.

\section{Personal Characteristics and Work Engagement}

Personal characteristics such as hardiness, self-efficacy, optimism, and pessimism have been evaluated with burnout (Lee \& Ashforth, 1996, Friedman, 2003). Much of this research has provided evidence for a "buffering effect" (Duquette, Kerouac, Sandhu, Ducharme, \& Saulnier, 1995, Riolli \& Savicki, 2003, Collins, 1996). That is, individuals under stressful conditions, who are high in a positive personal characteristic (e.g., optimism, hardiness, positive affectivity), are less likely to experience burnout than individuals who are low in positive personal characteristics. Limited research has extended the role that personal characteristics play with work engagement or its three dimensions. One study evaluated the relationship of hardiness with positive work experiences (Britt et al., 2001). This study's author, as noted earlier, found personality hardiness to be positively related to engagement in soldiers. This thesis, keeping with the mission of positive psychology, had the aim of finding a "vision of the good life" and "optimal work experiences". This thesis focused on the role of positive personal characteristics with work engagement (Seligman \& Csikszentmihalyi, p. 5). Hence, this 
thesis extended Riolli and Savicki's (2003) research on burnout by evaluating the role of optimism with work resources and work engagement.

\section{Optimism}

The relationship of optimism and work engagement has not been studied. In turn, this thesis defined optimism within the context of the research literature. "Optimism can be defined as the overwhelming tendency to presume that difficult situations and problems will be successfully managed and solved, and that everything will end positively" (Paulik, 2001, p. 93). Much of current research has evaluated optimism as a cognitive characteristic that describes goals, expectations, and attributions (Peterson, 2000). Although optimism has been considered to be a cognition, people also have very strong feelings about the object or topic of consideration (Peterson, 2000). Scheier and Carver (1985) explained that dispositional influences are important for predicting individuals' self-regulation. Generally, research has shown optimism to be related to numerous positive outcomes, such as higher job performance, higher motivation, successful coping, stronger academic performance, and lower strain (Tuten \& Neidermeyer, 2004; Macan, 2005). This research fit within the mission of positive psychology, noted earlier, and was expanded in this thesis.

The role that optimism plays with work resources and work engagement has not been examined. However, Riolli and Savicki's (2003) study is noteworthy because they reported a moderating effect of optimism with work resources and burnout. Evaluating the relationship of optimism with work resources is important to understand the degree to which a personal characteristic (optimism) influences the evaluation of work resources as 
negative, neutral, or positive (Hobfoll \& Freedy, 1990). Kahn (1990) argued that people vary in the degree to which they engage themselves in role performances based on their perception of the meaningfulness, availability and safety of the environment. Paulik (2001) argued that optimism is a requirement for an individual to appraise a situation as positive and engage in its management. Here, this thesis posited that individuals high in optimism experience greater work engagement. This is because they perceive their work environments to be more conducive to engaging themselves. In Peterson's (2000) discussion of optimism, he queried "Is the optimistic person experiencing flow: actively engaging in what he or she is doing while not self-consciously mindful (Csikszentmihalyi, 1990)?" (p. 49). In addition, Hobfoll and Freedy (1990) discussed the potential for an acceleration effect of resources on an intervention (i.e., that teaches the use of social support). The acceleration effect "suggests that those who have sufficient resources upon entry into groups will make best use of social support intervention in further refining their skills, knowledge, and coping capacity. Their current resources will accelerate the intervention's effects" (p. 100). Although research typically evaluates personality differences as dispositional, researchers have also described optimism as an explanatory style that can be learned (Hobfoll \& Freedy, 1990; Seligman \& Teasdale, 1978). From this approach, optimism could function like social support in Hobfoll and Freedy's (1990) study. The present study evaluated this acceleration effect with work resources and optimism. In sum, this thesis hypothesized that optimism would moderate the relationship of work resources with work engagement. 
Hypothesis 10: Optimism will moderate the relationship between work resources (coworker support for development, supervisor support for development, resource availability for development, and nonwork support for development) and vigor such that the relationship between work resources and vigor is stronger when optimism is high than when it is low.

Hypothesis 11: Optimism will moderate the relationship between work resources (coworker support for development, supervisor support for development, resource availability for development, and nonwork support for development) and dedication such that the relationship between work resources and dedication is stronger when optimism is high than when it is low.

Hypothesis 12: Optimism will moderate the relationship between work resources (coworker support for development, supervisor support for development, resource availability for development, and nonwork support for development) and absorption such that the relationship between work resources and absorption is stronger when optimism is high than when it is low. 
Method

\section{Participants}

Participants were obtained from two samples. The first sample of participants was selected from a non-profit organization composed of five small mental health facilities in the San Francisco Bay area. The second sample of participants contained employed university students from a large university located in the San Francisco Bay

area. Only employed participants from both organizations were included in the study. Participant details germane to each organization are provided in following subsections.

Participants from the non-profit organization.

A total of 63 completed surveys were obtained which resulted in a response rate of $40.38 \%$ for the organizational sample. The mean age was 34 years old, $(S D=11.49)$. Fifty four percent of the participants were women. Regarding tenure at the organization, employees had worked, on average, for 3.29 years, $(S D=3.27)$.

\section{Student participant information.}

Two hundred and twenty six surveys were collected from the student participants. Seventy-two of the 226 university students were not employed and thus were dropped from the sample, resulting in a total of 154 completed surveys. All course instructors provided the researcher with class time for survey administration. In addition, (with exception of one class) the course instructors provided research or extra credit to students for participation in the study. This resulted in a response rate of $93.39 \%$ for the university student sample. Seventy-one percent of student participants were female. In 
addition, the average age was 23.46 years old, $(S D=5.72)$. The average years working for their respective organizations were 2.36 years, $(S D=2.52)$.

\section{Procedure}

The researcher administered the survey directly to all participants. The survey entailed a paper and pencil design. Participation was anonymous. The researcher provided all participants with written informed consent. Specific procedural differences between the two samples are described in following subsections.

\section{Procedure for non-profit sample.}

The researcher contacted the program director of one of the organization's facilities to request the participation of the organization's staff in this research project. Once written consent was provided, the researcher contacted all program directors in writing and by telephone to inform them of the project and to schedule data collection times. The researcher requested all employees, including management, to fill out the survey. All five facilities participated in the study.

The survey was administered during breaks, at the beginning or end of shifts, and during meetings when their managers deemed appropriate. Participants were provided with several options for returning surveys. The researcher remained in the room with the participants to answer questions. In addition, the researcher left a locked drop-box, where participants could return their surveys at a later time.

\section{Procedure for student sample.}

The strategy for data collection among the student sample involved contacting faculty from the Business School, Department of Nursing, and the Department of 
Psychology at the university. Faculty members were selected based on availability and contacted via email to request a class time during which the surveys could be administered to students. One professor in the Nursing Department and four faculty members in the Psychology Department provided access to a total of six undergraduate classes.

Surveys were administered during class time. The researcher administered the surveys directly to all classes. Participants completing the survey were provided with informed consent. Steps were taken to ensure anonymity. More specifically, the researcher requested that participants place the survey into the provided drop box, without including their names on the survey.

Measures

Work Engagement. Work engagement was assessed on a three-dimensional scale called the Utrecht work engagement scale (UWES) developed by Schaufeli, Salanova, Gonzalez-Roma, and Bakker (2002). The three dimensions included vigor (6 items), dedication (5 items), and absorption (6 items). Vigor is a state where one experiences a high degree of energy, a strong work ethic, and an ability to persevere in spite of challenging work. A sample item is: "I feel strong and vigorous in my work". Dedication is a state where individuals are very involved with, inspired by, and proud about their work. They also perceive their work to be significant and describe difficulties as challenges rather than strains. A sample item is: "The work I do is full of meaning and purpose". Absorption in work entails being fully immersed in work and feeling happy about one's work roles. Individuals who are absorbed in their work perceive time 
to pass quickly and find it difficult to separate themselves from work tasks. A sample item is: "I get carried away when I am working". Respondents were asked to rate the extent of their agreement with the 17 items on the following scale: $1=$ Never, $2=$ Rarely, $3=$ Seldom, $4=$ Sometimes $/$ Occasionally, $5=$ Often, $6=$ Most of the time, and $7=$ Always. Vigor had a Cronbach alpha of .79, dedication had a Cronbach alpha of .90, and absorption had a Cronbach alpha of .82 .

Job Involvement. Job involvement was measured using Kanungo's (1982) scale. Job involvement reflects an employee's identification with their job. The individual reports feeling responsible for completing his/her job, and one's self-esteem is affected by his/her effectiveness in completing job-related tasks. A sample item is: "The most important things that happen to me involve my present job." Respondents were asked to rate the extent of their agreement with the ten items on the following scale: $1=$ Very Strongly Disagree, 2 = Strongly Disagree, $3=$ Disagree, $4=$ Neutral, $5=$ Agree, $6=$ Strongly Agree, and $7=$ Very Strongly Agree. This response format was modified from its original 6-point response format, for the sake of uniformity. Cronbach alpha was .94 .

Affective Commitment. Affective commitment was assessed using six items from Allen and Meyer (1990) and two items from Tetrick and Farkas (1988). Affective commitment is "an emotional attachment to, identification with, and involvement in the organization..." (Meyer, Stanley, Herscovitch, \& Topolnytsky, 2002, p. 21). For example, "This organization has a great deal of personal meaning for me." Respondents were asked to rate the extent of their agreement with eight items on the following scale: 1 
$=$ Very Strongly Disagree, $2=$ Strongly Disagree, $3=$ Disagree, $4=$ Neutral, $5=$ Agree, 6 $=$ Strongly Agree, and $7=$ Very Strongly Agree. Cronbach alpha was .83.

Work Resources. Work resources were measured using four situational support for development scales taken from Maurer, Weiss, and Barbeite (2003). Work resources included: development-oriented policies, coworker support for development, supervisor support for development, nonwork social support for development, and availability of learning and development resources. Coworker support for development (10 items) measures the degree to which coworkers, work peers, and subordinates support an employee's development of career skills. A sample item is: "My peers/coworkers are supportive of learning activities." Supervisor support for development (11 items) measures the support an employee's supervisor provides for developing his or her career skills. For example: "My supervisor provides adequate time for me to attend training." Learning and development resources available ( 8 items) refer to the policies toward and resources available for learning and development. This work resource combined two scales. Maurer et al. (2003) combined development-oriented policies (5-items) with learning and development resources available (3-items). The development-oriented policies pertain to the procedures, rules, and policies of the organization toward developing career relevant skills (e.g., "the policies and work rules where I am employed make it possible to participate in career related learning and development activities"). In contrast, the learning and development resources available items focus on the accessibility and opportunities for employees to develop their career skills (e.g., "Skill development options or learning materials can be obtained by me that will assist in 
improving my job/career skills"). Nonwork social support for development (8 items) focuses on the support that important people outside of work (e.g., friends, family, teachers, counselors) provide for the development of an employee's career relevant skills. A sample item is: "Friends outside of work are supportive of my efforts to improve my career skills." Respondents were asked to rate the extent of their agreement with all 36 items on the following scale: $1=$ Very Strongly Disagree, $2=$ Strongly Disagree, $3=$ Disagree, $4=$ Neutral, $5=$ Agree, $6=$ Strongly Agree, and $7=$ Very Strongly Agree. Cronbach alpha for coworker support for development was .94. Cronbach alpha for supervisor support for development was .95. Cronbach alpha for nonwork support for development was .82. Cronbach alpha for resource availability for development was .90 .

Optimism. Optimism was assessed using six items from the Extended Life Orientation Test (ELOT. Chang et al., 1997). Optimism refers to the belief that all events, problems, and difficulties will resolve positively. A sample item is: "In uncertain times, I usually expect the best." Respondents were asked to rate the extent of their agreement with each item on the following scale: $1=$ Strongly Disagree, $2=$ Disagree, 3 $=$ Neither Disagree Nor Agree, $4=$ Agree, and $5=$ Strongly Agree. Cronbach alpha for optimism was .76 .

Analyses

Prior to analyses, the data were checked for data entry errors, missing data by variable, missing data by participant, outliers, normality, and linearity. These steps also provided a general overview of the relationships of the variables. Data entry errors were checked manually. All 72 participants that reported the score " $2=$ Not Currently 
Employed" for student employment status were removed from the data set. One participant was missing all of his or her demographic responses and reported acquiescent responses to every scale. Therefore, this participant was dropped from further analyses. Another participant was found to have skipped a majority of the questions, and thus, was dropped from further analyses. All reverse-coded items were recoded. 


\section{Results}

In order to conduct hierarchical regression analyses, preliminary analyses were conducted; these analyses were factor analyses and inter-item correlations. The following section will describe the results of each of these preliminary analyses. After the description of these steps, tests of the hypotheses follow.

\section{Factor Analyses}

Principal Components Analyses (PCA) with direct oblimin rotation were conducted to verify the factor structure of the scales. Both exploratory and forced entry factor analyses were conducted for the different models.

Work Engagement. For the criterion variables vigor, dedication, and absorption, a forced factor PCA was conducted. See Table 1 for pattern matrix. The three dimensions were forced to three factors and explained a total of $61.18 \%$ of the variance. All dedication items loaded on the first factor, which accounted for $43.11 \%$ of the variance. Hence, all five dedication items were included. As seen in Table 1, five of the six vigor items loaded onto factor 2 accounting for an additional $10.65 \%$ of the variance. Three of the vigor items loaded on the first factor. Because two of the vigor items loaded

onto the first factor with dedication, they were deemed complex items. Although three of the vigor items did not load exclusively on the intended factor, the scale has been established in prior research with adequate internal reliability. Hence, the researcher deemed all items to be sufficient for inclusion in further reliability analysis. With the exception of one item, all absorption items loaded onto factor 3 accounting for another $7.42 \%$ of the variance. However, the last absorption item loaded onto the first two 


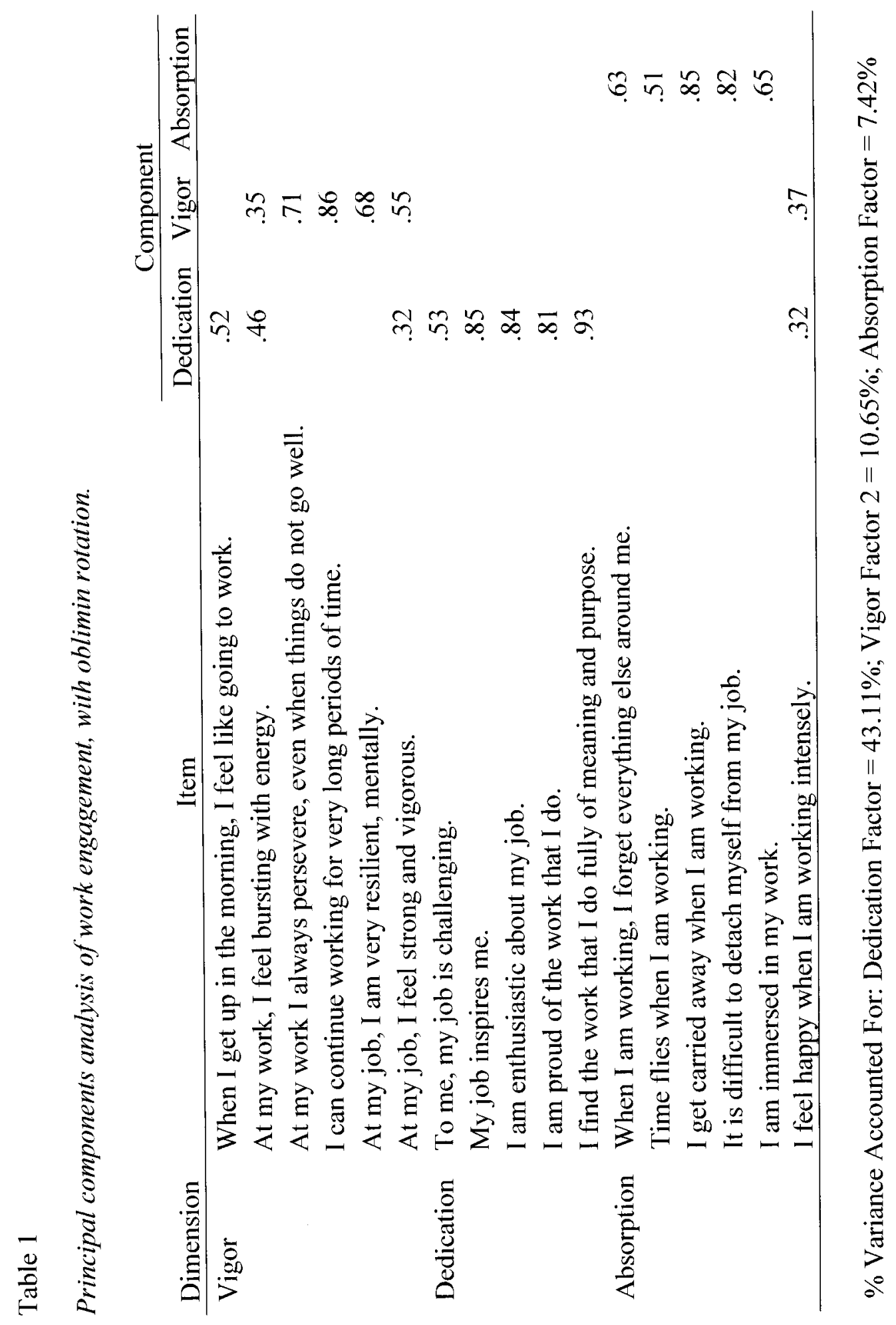


factors and was considered to be a complex item. This item: "I feel happy when I am working intensely" did not load onto the third factor. This item was most indicative of absorption. Therefore, all six absorption items were included.

Support for Development Constructs. Exploratory and forced factor Principal Components Analyses with direct oblimin rotation were conducted on Maurer et al.'s (2003) four support for development scales (see Table 2). With the exception of two reverse-coded items loading onto a fifth factor, the exploratory PCA revealed that the support for development items loaded onto the four scales as originally constructed by Maurer et al. The four factors: coworker support for development, supervisor support for development, policies/resource availability for development, and nonwork support for development accounted for a total of $66.41 \%$ of the variance.

Specifically, all eleven supervisor support for development items loaded onto Factor 1 accounting for $43.38 \%$ of the variance. One reverse-coded supervisor support for development item also loaded onto the fifth factor and was considered to be a complex item. Because only one item was found to have a complex loading, the researcher included all eleven items in the reliability analysis. Six of the seven nonwork support for development items loaded onto the second factor accounting for an additional $10.83 \%$ of the variance. The only reverse-coded nonwork support for development item: "People I trust (family, friends) have discouraged me from believing in myself when it comes to expanding my career skills" (reverse-coded) loaded onto factor 5, which explained an additional $3.39 \%$ of the variance to the total variance listed above. Again, the researcher deemed that the failure of only one item to load on the intended factor was 
Table 2

Exploratory principal components analysis of work resources, with oblimin rotation (see Appendix for items).

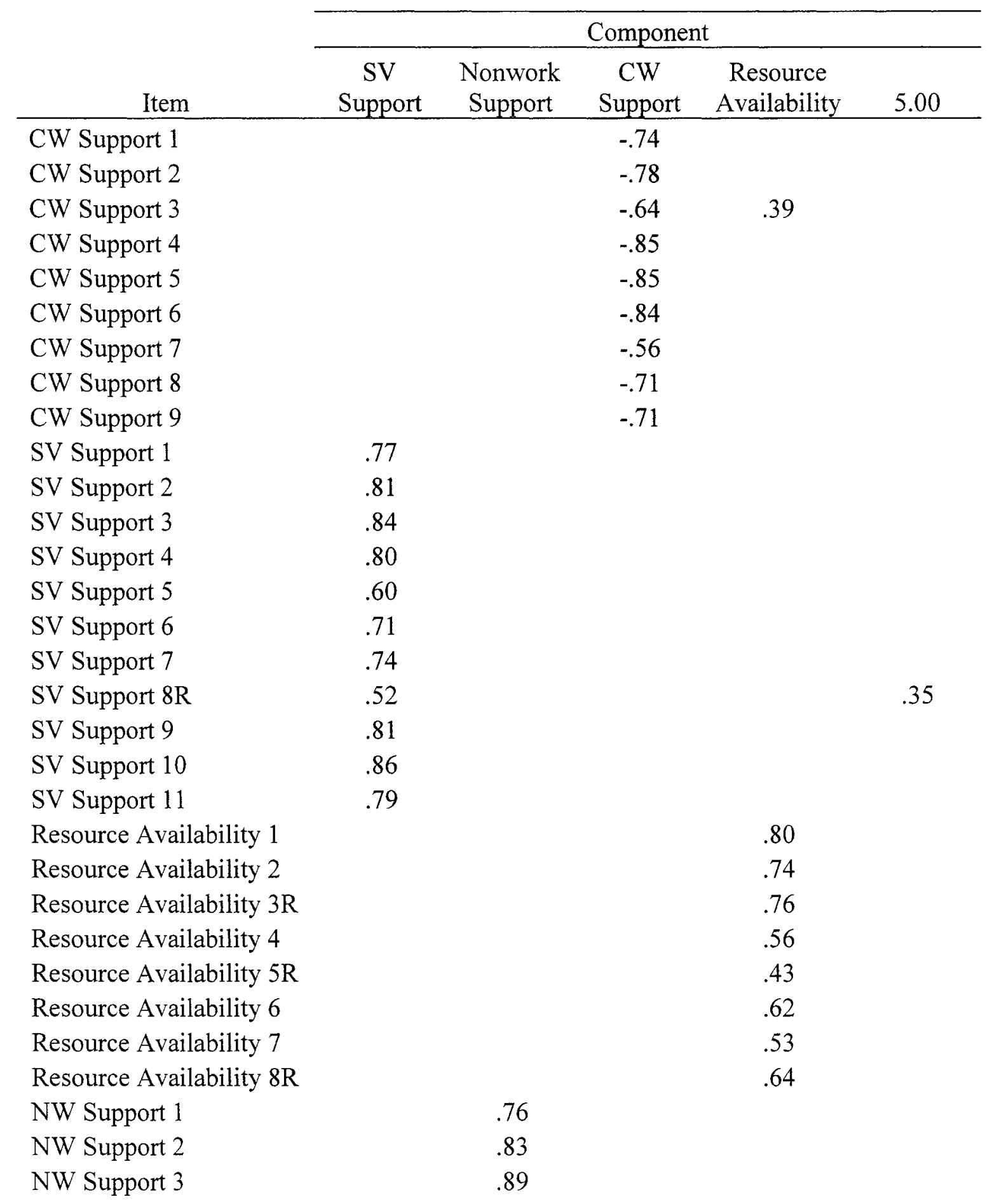


NW Support 4

NW Support 5

NW Support $6 \quad .71$

NW Support 7R $\quad .89$

Note: CW Support = Coworker Support for Development, SV Support $=$ Supervisor Support for Development,

Resource Availability = Policies/Resource Availability for Development, NW Support $=$ Nonwork Support for Development, \% Variance Accounted For: SV Support Factor: 43.38\%, Nonwork Support Factor: 10.83\%; CW Support Factor: 6.33\%, Resource Availability Factor: 5.59\% 
not problematic enough to remove it from an established scale. Hence, all seven nonwork support for development items were included in reliability analyses.

All nine coworker support for development items loaded onto the third factor, which accounted for an additional $6.63 \%$ of the variance. As a result of these loadings, all nine coworker support for development items were included in reliability analyses.

Lastly, all eight resource availability for development items loaded onto the fourth factor, which accounted for an additional $5.59 \%$ of the variance. The item: "my employer emphasizes employee learning to its employees" also loaded onto the third factor. Therefore, it was considered to be complex item. Again, all eight resource availability for development items were included in reliability analyses.

As anticipated, results of the forced factor model to four support for development factors revealed similar results as the exploratory factor model (see Table 3).

Maurer et al.'s sample revealed support for a two-factor model: work support for development, and nonwork support for development. Hence, a forced-factor PCA was conducted which forced the support for development items to two factors. From this analysis, the two factors explained a total of $54.20 \%$ of the variance. All coworker support for development, supervisor support for development, and resource availability for development items loaded onto the first factor accounting for $43.38 \%$ of the variance. The fourth and seventh coworker support for development items also loaded onto the second factor. These two items were considered to be complex. Six of the seven nonwork support for development items loaded onto the second factor, which accounted for an additional $10.83 \%$ of the variance. The only reverse-coded nonwork support for 
Table 3

Forced principal components analysis of work resources, with oblimin rotation (see Appendix for items).

\begin{tabular}{|c|c|c|c|c|}
\hline \multirow[b]{2}{*}{ Item } & \multicolumn{4}{|c|}{ Component } \\
\hline & $\begin{array}{c}\text { SV } \\
\text { Support }\end{array}$ & $\begin{array}{c}\mathrm{NW} \\
\text { Support }\end{array}$ & $\begin{array}{c}\text { CW } \\
\text { Support }\end{array}$ & $\begin{array}{l}\text { Resource } \\
\text { Availability }\end{array}$ \\
\hline CW Support 1 & & & -.79 & \\
\hline CW Support 2 & & & -.81 & \\
\hline CW Support 3 & & & -.76 & \\
\hline CW Support 4 & & & -.73 & \\
\hline CW Support 5 & & & -.77 & \\
\hline CW Support 6 & & & -.72 & \\
\hline CW Support 7 & & & -.57 & \\
\hline CW Support 8 & & & -.64 & \\
\hline CW Support 9 & & & -.66 & \\
\hline SV Support 1 & .81 & & & \\
\hline SV Support 2 & .83 & & & \\
\hline SV Support 3 & .86 & & & \\
\hline SV Support 4 & .83 & & & \\
\hline SV Support 5 & .63 & & & \\
\hline SV Support 6 & .72 & & & \\
\hline SV Support 7 & .77 & & & \\
\hline SV Support 8R & .58 & & & .33 \\
\hline SV Support 9 & .82 & & & \\
\hline SV Support 10 & .88 & & & \\
\hline SV Support 11 & .82 & & & \\
\hline Resource Availability 1 & & & & .67 \\
\hline Resource Availability 2 & & & -.35 & .59 \\
\hline Resource Availability & & & & \\
\hline $3 \mathrm{R}$ & & & & .74 \\
\hline Resource Availability 4 & & & & .50 \\
\hline Resource Availability & & & & \\
\hline $5 \mathrm{R}$ & & & & .44 \\
\hline Resource Availability 6 & & & -.35 & .56 \\
\hline Resource Availability 7 & & & -.45 & .43 \\
\hline Resource Availability & & & & \\
\hline $8 \mathrm{R}$ & & & & .66 \\
\hline NW Support 1 & & .76 & & \\
\hline
\end{tabular}


NW Support 2

NW Support 3

NW Support 4

NW Support 5

NW Support 6

NW Support 7R

$\%$ Variance Accounted For:

SV Support Factor: 43.38\%, Nonwork Support Factor: 10.83\%,

CW Support Factor: 6.33\%, Resource Availability Factor: 5.59\%
.83

.89

.88

.84

.70 
development item did not load onto the second factor, whereas, the nonwork support for development items, noted above, continued to reveal the highest factor loadings.

The results of the three Principal Components Analyses provided support for the four-factor model. Because the exploratory PCA resulted in the four factors, all four support for development scales were used in hypothesis testing. The researcher deemed the inclusion of four scales to add specificity to the prediction of the engagement dimensions. The inclusion of the four support for development dimensions isolates the relationship of support from coworkers, supervisors, non-work members, or the availability of learning resources with the amount of vigor, dedication, or absorption one experiences. Therefore, reliability analyses were conducted for the four support for development scales rather than the two reduced factor scales.

Job Involvement. With regard to job involvement, a forced one-factor solution revealed all ten job involvement items to load onto the one factor (see Table 4). This factor accounted for $41.45 \%$ of the variance.

Affective Commitment. A forced one-factor PCA revealed all ten affective commitment items to load onto one factor (see Table 5). This factor accounted for $46.16 \%$ of the variance.

Optimism. Exploratory and forced-factor Principal Components Analyses were conducted for the six optimism items (see Table 6). Both extraction methods revealed one factor, which accounted for $47.44 \%$ of the variance. 
Table 4

Forced principal components analysis of job involvement, with oblimin rotation.

\begin{tabular}{lc}
\multicolumn{1}{c}{ Item } & $\begin{array}{c}\text { Component } \\
\end{array}$ \\
\hline & $\begin{array}{c}\text { Job } \\
\text { Involvement }\end{array}$ \\
The most important things that happen to me involve my present job. & .75 \\
To me, my job is only a small part of who I am. (R) & .67 \\
I am very much involved personally in my job. & .79 \\
I live, eat and breathe my job. & .79 \\
Most of my interests are centered around my job. & .59 \\
I have very strong ties with my present job, which would be very & .32 \\
difficult to break. & .74 \\
Usually I feel detached from my job. & .65 \\
Most of my personal life goals are job-oriented. & .53 \\
I consider my job to be very central to my existence. & .43 \\
\hline
\end{tabular}

\% Variance Accounted For:

Job Involvement Factor 1: 41.45\% 
Table 5

Forced principal components analysis of affective commitment, with oblimin rotation.

\begin{tabular}{lc}
\multicolumn{1}{c}{ Item } & $\begin{array}{c}\text { Component } \\
\text { Affective } \\
\text { Commitment }\end{array}$ \\
\hline $\begin{array}{l}\text { I would be very happy to spend the rest of my career in this } \\
\text { organization. }\end{array}$ & .62 \\
I really feel as if this organization's problems are my own. & .59 \\
I do not feel like "part of the family" at my organization. (R) & .75 \\
I do not feel "emotionally attached" to this organization. (R) & .72 \\
This organization has a great deal of personal meaning for me. & .78 \\
I do not feel a strong sense of belonging to my organization. (R) & .77 \\
I find that my values and the organization's values are very similar. & .63 \\
Often, I find it difficult to agree with the organization's policies on & .52 \\
important matters relating to its employees. (R) &
\end{tabular}

$\%$ Variance Accounted For:

Affective Commitment Factor: $46.16 \%$ 
Table 6

Exploratory principal components analysis of optimism, with oblimin rotation.

\begin{tabular}{lc}
\multicolumn{1}{c}{ Item } & Component \\
\cline { 2 - 2 } In uncertain times, I usually expect the best. & .48 \\
I always look on the bright side of things. & .74 \\
I'm always optimistic about my future. & .76 \\
When I undertake something new, I expect to & .72 \\
succeed. & .74 \\
Where there's a will, there's a way. & .66 \\
In general, things turn out alright in the end. & \\
\hline
\end{tabular}

$\%$ Variance Accounted For:

Optimism Factor: $47.44 \%$ 


\section{Descriptive Statistics}

Descriptive statistics were conducted for all eleven predictor variables in addition to the criterion variables: vigor, dedication, and absorption. All scales were from 1 to 7 except optimism, which had a response scale of 1 to 5 . Scale means for vigor, dedication, and absorption were $5.01,4.82$, and 4.06 , respectively, suggesting that employees are generally engaged in their jobs. These results indicate that individuals are not as absorbed in their jobs as they are dedicated or vigorous. The standard deviation for vigor was .83 , whereas the standard deviations for dedication and absorption were 1.34 and 1.07 , respectively.

With regard to the four support for development scales, coworker support for development, supervisor support for development, and resource availability for development had mean ratings of $4.87,4.98$, and 4.93 , respectively. Non-work support for development had a mean of 5.72. Overall, the support for development means indicate that individuals moderately agree that they receive support for development at work. The higher mean for non-work support for development indicates that, generally, participants received much higher support for development from individuals outside of work than from work.

For work attitudes, affective commitment and job involvement had mean scores of 4.18 and 3.53 , respectively. Participants were neutral or only slightly agreed with the statement that they felt a strong sense of belonging and meaning to the organization. However, they slightly disagreed that they identified with their jobs or that their interests were "centered around [their] job" (Kanungo, p. 342). 
Lastly, the mean score for optimism was 4.03 . The standard deviation for this variable was .56, which was considered low. These statistics indicate that participants were generally optimistic and did not substantially vary in their ratings. For all means and standard deviations see Table 7.

\section{Correlations for Vigor}

Correlations were run for the eleven variables along with the three criterion variables: vigor, dedication, and absorption (see Table 7). Vigor was found to be related to the other criterion variables: dedication $(r=.59, p<.05)$, and absorption $(r=.54, p<$ .05). Also, all four dimensions of work resources correlated with vigor $(r=.43, r=.42, r$ $=.42, r=.24, p<.05$; coworker support for development, supervisor support for development, resource availability for development, and nonwork support for development, respectively). With regard to the work attitude variables and the personal characteristic variable, vigor was related to affective commitment $(r=.46, p<.05)$, job involvement $(r=.37, p<.05)$, and optimism $(r=.38, p<.05)$. In conclusion, all four work resources correlated with vigor. Nonwork support for development had the weakest correlation. In addition, individuals' ratings (i.e., affective commitment and job involvement) had moderate positive relationships with vigor.

\section{Correlations for Dedication}

Dedication was related to vigor, as noted above, and absorption $(r=.67, p<.05)$. In addition, dedication was related to the four work resource variables $(r=.60, r=.54, r$ $=.64, r=.22, p<.05 ;$ coworker support for development, supervisor support for development, policy/resource availability for development, and nonwork support for 


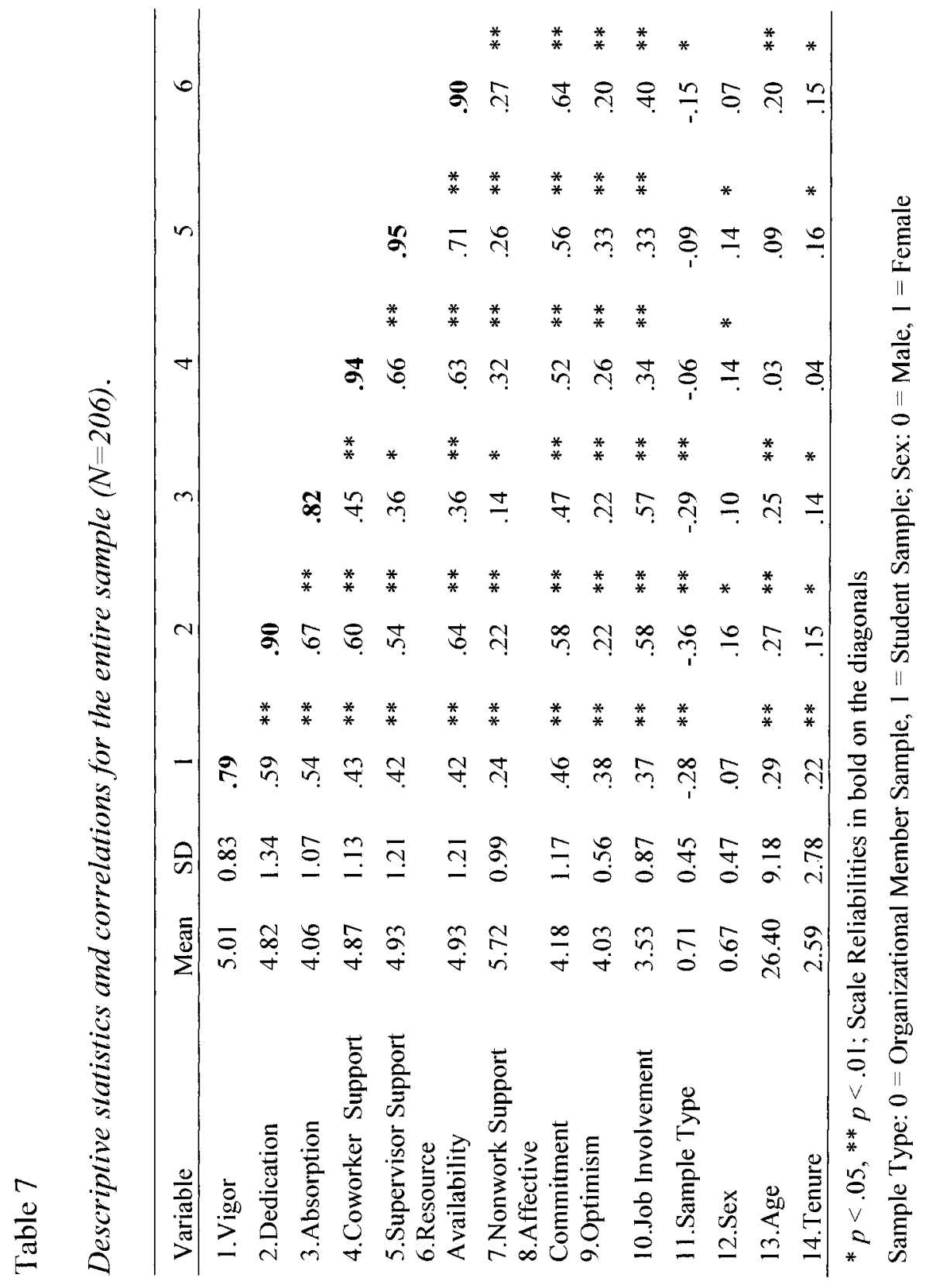




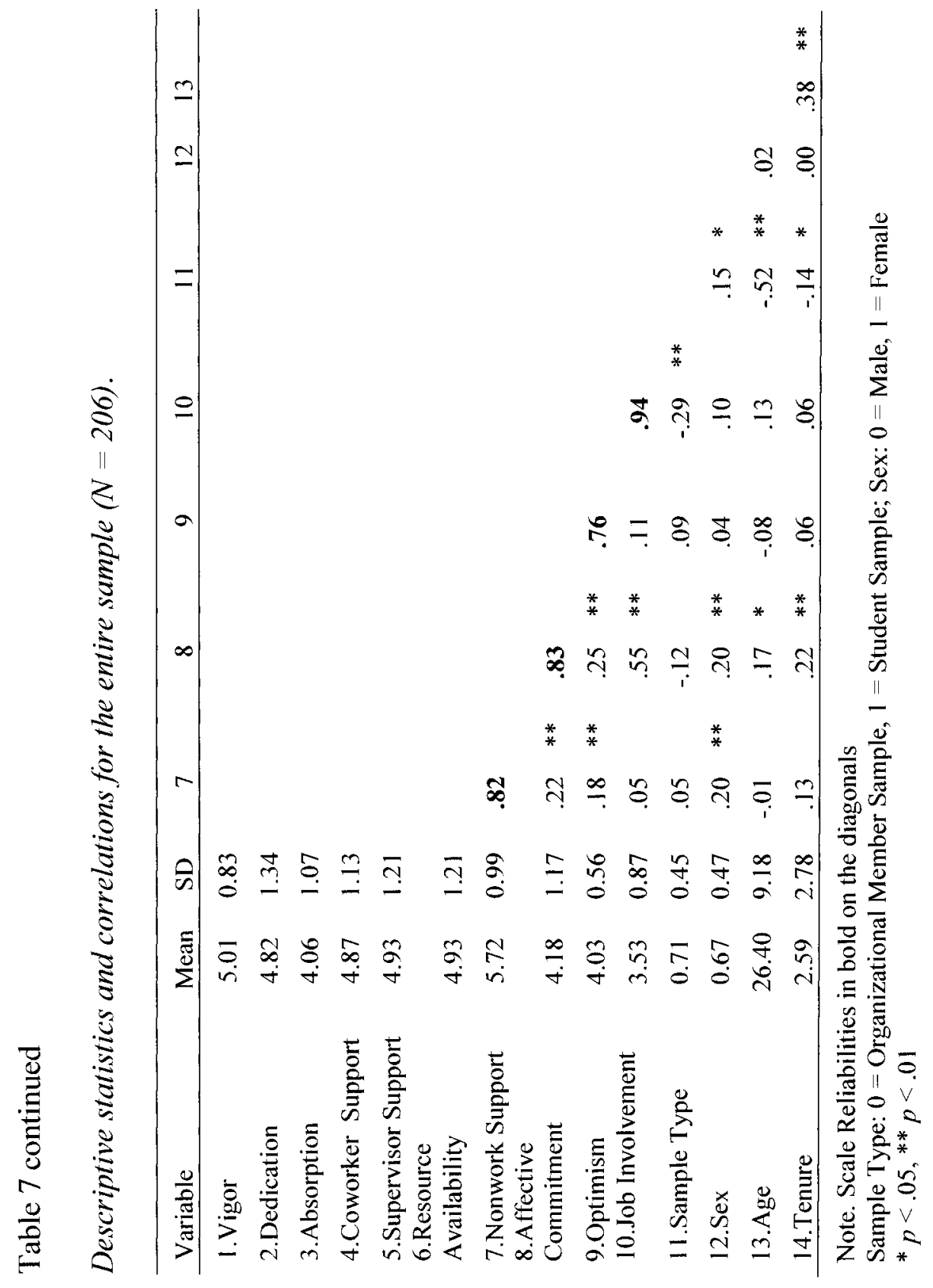


development, respectively). These results indicate that the four work resource variables are moderately related to dedication. Similar to vigor, nonwork support for development emerged as the least related work resource. With regard to the work attitude variables and the personal characteristic variable, dedication was related to affective commitment $(r=.46, p<.05)$, job involvement $(r=.37, p<.05)$, and optimism $(r=.22, p<.05)$. In conclusion, affective commitment, job involvement, and optimism were moderately related to dedication.

\section{Correlations for Absorption}

With regard to absorption, significant relationships were found between absorption and the four work resource variables $(r=.45, r=.36, r=.36 r=.14, p<.05$; coworker support for development, supervisor support for development, resource availability for development, and nonwork support for development, respectively). These results indicate moderate, positive relationships between the four work resources and absorption. Similar to vigor and dedication, nonwork support for development was the least related to absorption. With regard to the work attitude variables and personal characteristic variable, absorption was related to affective commitment $(r=.47, p<.05)$, job involvement $(r=.57, p<.05)$, and optimism $(r=.22, p<.05)$. In conclusion, moderate positive relationships were found between each of the predictors (i.e., the four work resources, affective commitment, job involvement, and optimism) and absorption, respectively. 


\section{Correlations for Demographic Variables}

With the exception of sex, all of the demographic variables significantly related with vigor, dedication, and absorption. Correlations were low to moderate and ranged from .14 to .29 . Sex only significantly related with dedication $(r=.16, p<.05)$, which indicates that women were more dedicated than men. Therefore, this demographic variable was excluded from further analyses with vigor and absorption. These relationships indicated that tenure, sample type, age, and sex (with dedication) should be controlled when testing the hypothesized relationships of interest for this study.

\section{Hierarchical Moderated Regression Analyses}

Hypotheses 1-3 predicted that after controlling for demographic characteristics (sample type, sex, age, and tenure), there would be significant relationships between the four work resources and the three work engagement outcomes: vigor, dedication, and absorption. Hypotheses 4-9 predicted that job involvement and affective commitment would predict vigor, dedication, and absorption above and beyond the four demographic characteristics. Hypotheses 9-12 predicted that optimism would moderate the relationship of work resources and vigor, dedication, and absorption, respectively. To test these hypotheses, hierarchical moderated regression analyses were conducted for each of the three criterion variables.

\section{Hierarchical Moderated Regression for Vigor}

In step one of the hierarchical regression for predicting vigor, demographic variables (i.e., sample type, age, and tenure) accounted for a significant (12\%) proportion of the variance in vigor $\left[R=.35, R^{2}=.12, R^{2}\right.$ adj. $=.11, F$ cha $\left.(3,204)=9.60, p<.01\right]$. 
However, only one demographic variable (i.e., sample type) was uniquely related to vigor, with the resulting beta weight $(\beta=-.19, p<.05)$. This unique beta weight indicated that participants in the organizational sample experienced more vigor than those in the student sample.

In step two of the hierarchical moderated regression (after controlling for the relationship of demographic variables), the four support for development variables affective commitment, job involvement, and optimism were entered $\left[R=.65, R^{2}=.43\right.$, $R^{2}$ adj. $=.40, \Delta R^{2}=.31, F$ cha $\left.(10,197)=14.82, p<.01\right]$. As a set, the predictor variables explained an additional $31 \%$ of the variance above and beyond the control variables. However, the only significant predictors were coworker support for development $(\beta=$ $.17, p<.05)$ and optimism $(\beta=.28, p<.01)$. These results provide partial support for Hypotheses 1.

In step three of the hierarchical moderated regression, a significant interaction was found between the cross products of the four work resource variables with optimism and vigor $\left[R=.67, R^{2}=.45, R^{2} \text { adj } .=.41, \Delta R^{2}=.03, F \text { cha }(14,193)=2.35, p<.10\right]^{1}$. As a set, the cross products (i.e., coworker support for development $\mathrm{x}$ optimism, supervisor support for development $\mathrm{x}$ optimism, resource availability for development $\mathrm{x}$ optimism, and nonwork support for development $\mathrm{x}$ optimism) explained an additional $3 \%$ of the variance above and beyond the control variables and the predictor variables alone. However, no single cross product had a statistically significant Beta weight (see Table 8). 
Table 8

Regression analysis predicting vigor $(N=209)$.

\begin{tabular}{|c|c|c|c|c|c|}
\hline \multirow{2}{*}{$\frac{\text { Step }}{1}$} & \multirow{2}{*}{$\begin{array}{ll} & \text { Predictor } \\
\text { Sample Type } & \end{array}$} & \multicolumn{2}{|l|}{$\beta$} & \multicolumn{2}{|c|}{$\Delta \mathrm{R}^{2}$} \\
\hline & & -.19 & * & .12 & $* *$ \\
\hline & Age & .14 & & & \\
\hline & Tenure & .14 & & & \\
\hline 2 & Coworker Support for Development & .17 & $*$ & .31 & * \\
\hline & Supervisor Support for Development & .04 & & & \\
\hline & Policies/Resources for Development & .02 & & & \\
\hline & Nonwork support for Development & .09 & & & \\
\hline & Affective Commitment & .13 & & & \\
\hline & Job Involvement & .11 & & & \\
\hline & Optimism & .28 & $* *$ & & \\
\hline 3 & Coworker Support for Development x Optimism & .49 & & .03 & $\dagger$ \\
\hline & Supervisor Support for Development x Optimism & 1.16 & & & \\
\hline & $\begin{array}{l}\text { Policy/Resources for Development x Optimism } \\
\text { Nonwork support for Skill Development x }\end{array}$ & -.17 & & & \\
\hline & Optimism & .27 & & & \\
\hline
\end{tabular}

Note. $\beta$ values are reported after the main effects have been entered

$\beta$ values are taken from second step of coefficient table.

Sample Type: $0=$ Organization Employees, $1=$ University

Students

Sex: $0=$ Male, $1=$ Female

$\dagger \mathrm{p}<.1, * \mathrm{p}<.05, * * \mathrm{p}<.01$ 
Once the interaction between the four work resources, optimism, and vigor was found to be significant, simple linear regressions were conducted to provide prediction equations for graphing. Because none of the interactions of the cross products (between the four work resources with optimism and vigor) had significant beta weights, a new composite "work resources" variable was computed. This new composite variable combined all four support for development scales (by item level) into one scale mean. The scale mean was entered into the prediction equation. In addition, optimism was dichotomized by its median in order to evaluate the moderating role of optimism on the relationship between work resources and vigor. Hence, low optimism was computed as optimism scores less than 4 , and high optimism was computed as optimism scores greater than 4 (on a five-point scale where $5=$ highest optimism; see Table 9 and Figure 1 ). In addition, correlations were conducted for the dichotomized optimism scale to evaluate whether the work resources-vigor relationship was stronger for high optimism than for low optimism. The correlation analysis revealed that the relationship of work resources and vigor was stronger when optimism was high $(\beta=.59, p<.01)$ than when optimism was low $(\beta=.33, p<.01)^{2}$. This analysis provided some support for Hypothesis 10 . Although the interaction was found to be significant, the increase in variance explained was only $3 \%$.

Provided that the explanatory power of the interaction was small, a specific pattern of results did emerge. Specifically, when work resources were high, individuals who were high in optimism were likely to experience greater vigor than individuals low in optimism. However, when work resources were low, individuals who were high in 
Table 9

Linear Regressions for the Interaction of Optimism with Vigor $(N=214)$.

Predicting Vigor from Low Optimism

\begin{tabular}{|c|c|c|c|c|}
\hline Step & & $\mathrm{B}$ & $\beta$ & \\
\hline \multirow[t]{2}{*}{1} & Constant & 3.23 & & \\
\hline & Work Resources & .32 & .33 & * \\
\hline \multicolumn{5}{|c|}{ Predicting Vigor from High Optimism } \\
\hline Step & & $\mathrm{B}$ & $\beta$ & \\
\hline \multirow[t]{2}{*}{1} & Constant & 2.37 & & \\
\hline & Work Resources & .54 & .59 & * \\
\hline
\end{tabular}

$* \mathrm{p}<.01$ 


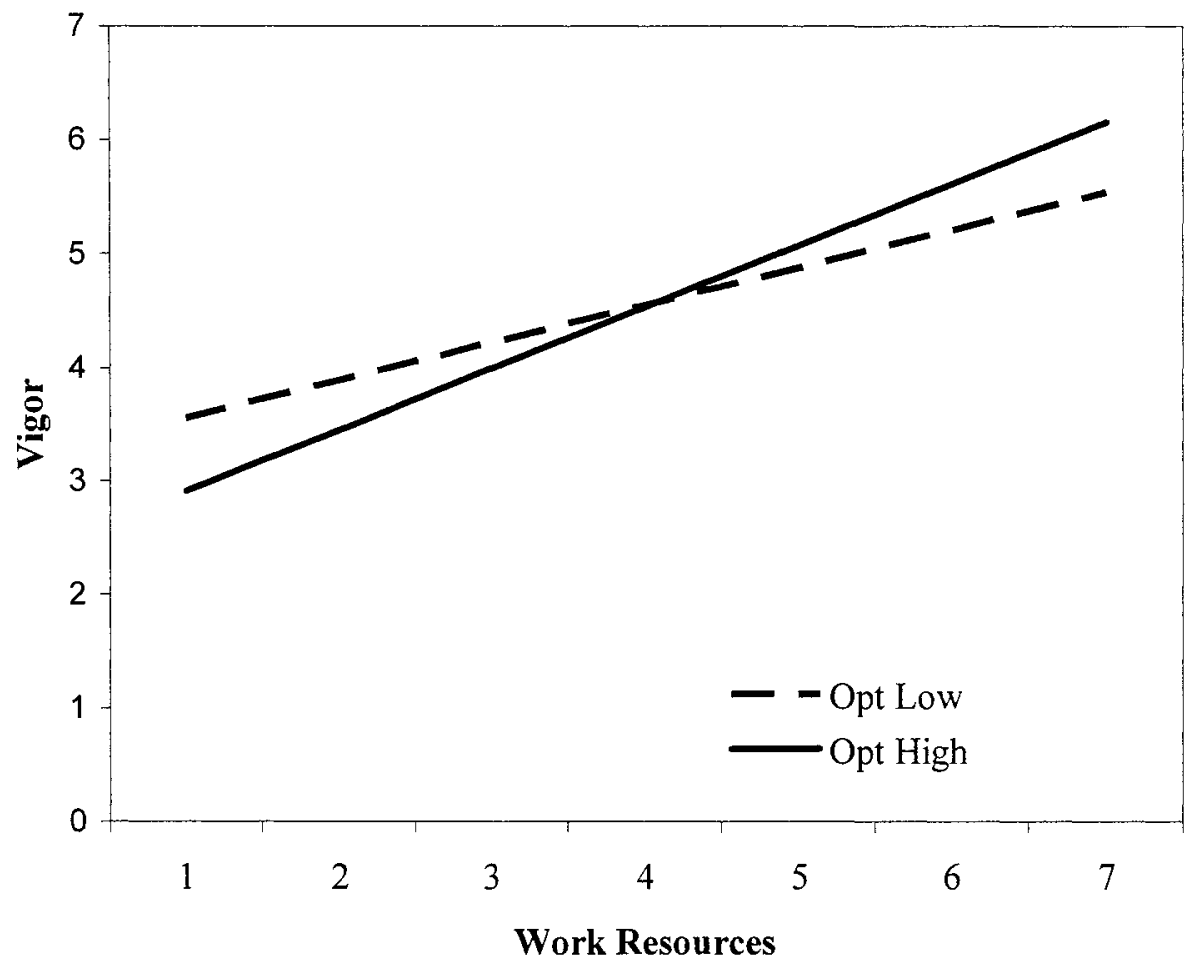

Figure 1: Moderating Effect of Optimism on Work Resources and Vigor 
optimism were likely to experience less vigor than individuals who were low in optimism.

\section{Hierarchical Moderated Regression for Dedication}

In step one of the hierarchical regression for predicting dedication, demographic variables (i.e., sample type, age, sex, and tenure) accounted for a significant (19\%) proportion of the variance in dedication $\left[R=.44, R^{2}=.19, R^{2}\right.$ adj. $=.18, F$ cha $(4,201)=$ $11.89, p<.01]$. Sample type $(\beta=-.36, p<.0001)$ and $\operatorname{sex}(\beta=.21, p<.01)$ emerged as the most important predictors of dedication. These beta weights indicate that organizational members experienced greater dedication than student participants; in addition, women experienced greater dedication than men.

In step two of the hierarchical moderated regression (after controlling for the relationship of the four demographic variables), affective commitment, job involvement, and optimism were entered $\left[R=.80, R^{2}=.64, R^{2}\right.$ adj. $=.62, \Delta R^{2}=.45, F$ cha $(4,194)=$ $34.66, p<.01]$. As a set, the predictor variables explained an additional $45 \%$ of the variance above and beyond the control variables. However, only $\operatorname{sex}(\beta=.02, p<.05)$, coworker support for development $(\beta=.26, p<.01)$, resource availability for development $(\beta=.28, p<.01)$, and job involvement $(\beta=28, p<.01)$ emerged as significant predictors of dedication. This step provided partial support for Hypotheses 2

and 8. Because the beta weight of affective commitment was non significant, Hypothesis 5 was not supported (see Table 10).

In step three of the hierarchical moderated regression, a moderating effect was tested between the cross products of the four work resource variables and optimism $[R=$ 
Table 10

Regression analysis predicting dedication $(N=206)$.

\begin{tabular}{|c|c|c|c|c|c|}
\hline \multirow{2}{*}{$\frac{\text { Step }}{1}$} & \multirow{2}{*}{$\begin{array}{ll} & \text { Predictor } \\
\text { Sample Type } & \end{array}$} & \multicolumn{2}{|c|}{$\beta$} & \multicolumn{2}{|c|}{$\Delta \mathrm{R}^{2}$} \\
\hline & & -.36 & ** & .19 & $* *$ \\
\hline & Age & .05 & & & \\
\hline & Tenure & .08 & & & \\
\hline & Sex & .21 & ** & & \\
\hline 2 & Coworker Support for Development & .26 & ** & .45 & * \\
\hline & Supervisor Support for Development & -.03 & & & \\
\hline & Policies/Resources for Development & .28 & ** & & \\
\hline & Nonwork support for Development & .02 & & & \\
\hline & Affective Commitment & .04 & & & \\
\hline & Job Involvement & .28 & ** & & \\
\hline & Optimism & .08 & & & \\
\hline 3 & Coworker Support for Development x Optimism & .10 & & .01 & \\
\hline & Supervisor Support for Development x Optimism & .76 & & & \\
\hline & $\begin{array}{l}\text { Policy/Resources for Development x Optimism } \\
\text { Nonwork support for Skill Development x }\end{array}$ & -.32 & & & \\
\hline & Optimism & -.06 & & & \\
\hline
\end{tabular}

Note. $\beta$ values are reported after the main effects have been entered $\beta$ values are taken from second step of coefficient table.

Sample Type: $0=$ Organization Employees, $1=$ University Students

Sex: $0=$ Male, $1=$ Female

$\uparrow \mathrm{p}<.1,{ }^{*} \mathrm{p}<.05, * * \mathrm{p}<.01$ 
$.80, R^{2}=.65, R^{2}$ adj. $=.62, \Delta R^{2}=.01, F$ cha $(4,190)=.75, p=$ n.s. $]$. Hence, the interaction of the cross products (of the four work resources and optimism) was not significant for predicting dedication. Hypothesis 11 was not supported.

\section{Hierarchical Moderated Regression for Absorption}

In step one of the hierarchical moderated regression for predicting absorption, demographic variables (i.e., sample type, age, and tenure) accounted for a significant $(10 \%)$ proportion of the variance in absorption $\left[R=.32, R^{2}=.10, R^{2}\right.$ adj. $=.08, F$ cha $(3,204)=7.48, p<.01]$. However, only one demographic variable (i.e., sample type) was significantly related to absorption, with the resulting beta weight $(\beta=-.22, p<.01)$. This unique beta weight indicated that participants in the organizational sample experienced greater absorption than university student participants.

In step two of the hierarchical regression after controlling for the relationship of the three demographic variables (i.e., sample type, age, and tenure), the four support for development variables, affective commitment, job involvement, and optimism were entered $\left[R=.67, R^{2}=.45, R^{2}\right.$ adj. $=.42, \Delta R^{2}=.35, F$ cha $\left.(4,193)=18.07, p<.01\right]$. As a set, the predictor variables explained an additional $35 \%$ of the variance above and beyond the control variables. However, only coworker support for development $(\beta=.26, p<$ $.01)$ and job involvement $(\beta=.40, p<.01)$ emerged as significant predictors of absorption. These findings provided partial support for Hypothesis 3. Job involvement's beta weight provides support for it as the most important predictor of absorption. Hence, Hypothesis 9 was supported (See Table 11). 
Table 11

Regression analysis predicting absorption $(N=208)$.

\begin{tabular}{|c|c|c|c|c|c|}
\hline \multirow{2}{*}{$\frac{\text { Step }}{1}$} & \multirow{2}{*}{$\begin{array}{ll} & \text { Predictor } \\
\text { Sample Type } & \end{array}$} & \multicolumn{2}{|c|}{$\beta$} & \multicolumn{2}{|c|}{$\Delta \mathrm{R} 2$} \\
\hline & & -.22 & ** & .10 & $* *$ \\
\hline & Age & .11 & & & \\
\hline & Tenure & .06 & & & \\
\hline \multirow[t]{7}{*}{2} & Coworker Support for Development & .26 & $* *$ & .35 & * \\
\hline & Supervisor Support for Development & -.08 & & & \\
\hline & Policies/Resources for Development & .05 & & & \\
\hline & Nonwork support for Development & .01 & & & \\
\hline & Affective Commitment & .06 & & & \\
\hline & Job Involvement & .40 & $* *$ & & \\
\hline & Optimism & .12 & * & & \\
\hline \multirow[t]{4}{*}{3} & Coworker Support for Development x Optimism & -.76 & & .02 & $\dagger$ \\
\hline & Supervisor Support for Development x Optimism & .81 & & & \\
\hline & $\begin{array}{l}\text { Policy/Resources for Development x Optimism } \\
\text { Nonwork support for Skill Development x }\end{array}$ & .84 & & & \\
\hline & Optimism & -.51 & & & \\
\hline
\end{tabular}

Note. $\beta$ values are reported after the main effects have been entered $\beta$ values are taken from second step of coefficient table.

Sample Type: $0=$ Organization Employees, $1=$ University Students

Sex: $0=$ Male, $1=$ Female; $\uparrow \mathrm{p}<.1, * \mathrm{p}<.05,{ }^{* *} \mathrm{p}<.01$ 
In step three of the hierarchical moderated regression, a moderating effect was tested between the cross products of the four work resource variables and optimism $[R=$ $.69, R^{2}=.47, R^{2}$ adj. $=.44, \Delta R^{2}=.02, F$ cha $\left.(4,193)=2.03, p<.10\right]$. As a set, the cross products (i.e., coworker support for development x optimism, supervisor support for development $\mathrm{x}$ optimism, resource availability for development $\mathrm{x}$ optimism, and nonwork support for development $\mathrm{x}$ optimism) explained an additional $2 \%$ of the variance in absorption above and beyond the control variables and the predictor variables alone. However, no single cross product had a statistically significant Beta weight.

Once the interaction was found to be significant, simple linear regressions were run to provide prediction equations for graphing. Because none of the interactions of the four work resources had significant interactions, a new composite "work resources" variable was computed and entered into the prediction equation, similar to the steps taken for vigor. Again, optimism was dichotomized by its median (i.e., 4 out of 5) in order to evaluate its moderating effect at low and high levels (see Table 12 and Figure 2). In addition, correlations were run for the dichotomized optimism scale to evaluate whether the work resources-absorption relationship was stronger for high optimism than for low optimism. The correlation analysis revealed that the relationship of work resources and absorption was stronger for high optimism $(\beta=.50, p<.01)$ than for low optimism $(\beta=$ $.36, p<.01)$. This analysis provides limited support Hypothesis 12. Similar to the interaction found with vigor, the increase in variance explained was only $2 \%$.

Provided that the explanatory power of the interaction was small, a specific pattern of results did emerge. Specifically, when work resources were high, individuals 
Table 12

Linear Regressions for the Interaction of Optimism with Absorption $(N=214)$.

Predicting Absorption from Low Optimism

\begin{tabular}{|c|c|c|c|}
\hline Step & B & $\beta$ & \\
\hline 1 Constant & 1.81 & & \\
\hline Work Resources & .44 & .36 & * \\
\hline \multicolumn{4}{|c|}{ Predicting Absorption from High Optimism } \\
\hline Step & $\mathrm{B}$ & $\beta$ & \\
\hline 1 Constant & .85 & & \\
\hline Work Resources & .63 & .50 & * \\
\hline
\end{tabular}

$* \mathrm{p}<.01$ 


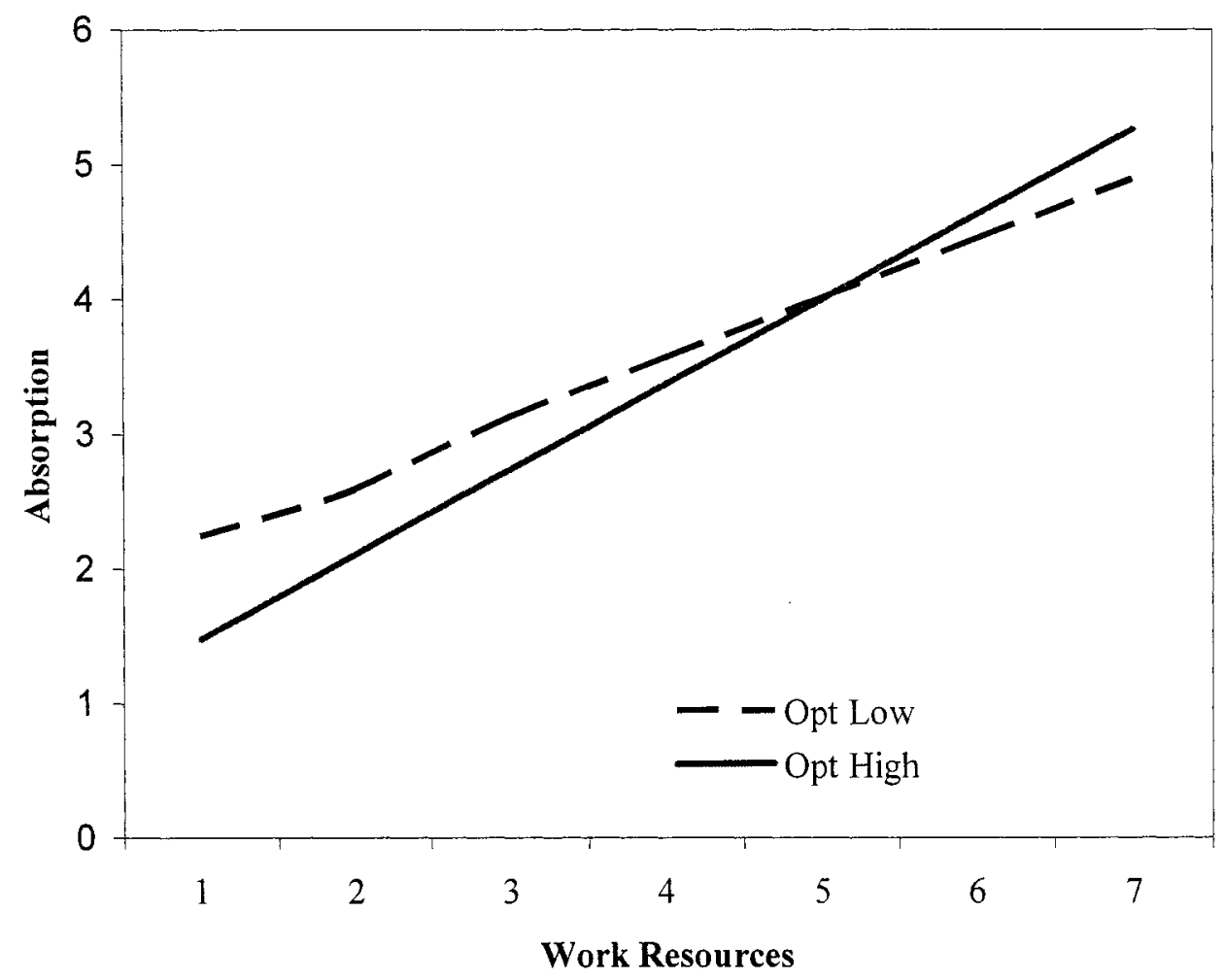

Figure 2: The Moderating Effect of Optimism on Work Resources and Absorption 
who were high in optimism were likely to be more absorbed than individuals low in optimism. However, when work resources were low, individuals who were high in optimism were likely to be less absorbed than individuals who were low in optimism. 


\section{Discussion}

The current study examined the relationship of work resources, affective commitment, job involvement, and optimism with work engagement in university students and non-profit organization members. The results of the hierarchical moderated regression analyses provide partial support for Hypotheses 1, 2, 3, 10 and 12, and full

support for Hypotheses 8 and 9. After the demographic predictors (i.e., sample type, sex, age, and tenure) were controlled, several significant relationships emerged: coworker support for development predicted a significant amount of the variance in vigor, dedication, and absorption; resource availability for development and job involvement predicted dedication; and optimism predicted vigor and absorption.

After controlling for demographic variables, coworker support for development and optimism emerged as the strongest predictors for vigor. This analysis provided partial support for Hypotheses 1 and 10. After controlling for demographic variables, work resources, work attitudes, and optimism, limited evidence was found for the moderating effect of optimism. Specifically, the relationship between work resources and vigor is stronger when individuals are highly optimistic than when they are low in optimism. This finding provided limited support for Hypothesis 10.

Coworker support for development, resource availability for development, and job involvement emerged as the strongest predictors of dedication, after controlling for demographic variables. This result provided partial support for Hypothesis 2 and full support for hypothesis 8 . Optimism did not moderate the relationship between work resources and dedication. Hence, Hypothesis 11 was not supported. 
After controlling for demographic variables, coworker support for development and job involvement emerged as the strongest predictors of absorption. This analysis provided partial support for Hypotheses 3 and full support for Hypothesis 8. In addition, after controlling for demographic variables, work resources, work attitudes, and optimism, limited evidence was found for the moderating effect of optimism. Specifically, the relationship between work resources and absorption is stronger when individuals are high in optimism than when they are low in optimism. These findings provided limited support for Hypothesis 12.

Lastly, the findings indicate that the interaction effect of optimism combined with work resources explains a small but unique amount of the variance in vigor and absorption above and beyond the other predictor variables. In conclusion, this study provides some support for a positive relationship between work resources, work attitudes, optimism, and each of the three work engagement dimensions (i.e., vigor, dedication, and absorption). In addition, this study provides support for a small moderating role of optimism with work resources, vigor and absorption.

\section{Strengths and Limitations}

One strength of this study is that it included two samples: employees of a nonprofit organization, and employed university students. Including two samples increases the generalizability of the results to other work populations. Another strength of the study is that it provides further empirical support for Demerouti et al.'s (2001) Job Demands-Resources model. More specifically, the JD-R model provided a framework to explain how work resources relate to vigor, dedication, and absorption. 
The study's findings should also be considered with regard to its limitations. One limitation is the strong relationship that sample type had with the criterion variables. In this study, the variable sample type, defined as members of the non-profit organization and students at the university, was controlled. The analysis of sample type as a control variable indicated that being a member of the organizational sample significantly predicted vigor, dedication, and absorption. This finding limits the generalizability of the study to some extent. However, the types of organizations where the different students worked was not controlled. Hence, the results might only apply to employees who work in a non-profit organization rather than to all working people. Because this thesis did not control for organization type, this implication can not be determined.

Another limitation of the study was that it used only self-report survey data. This method results in common method/common source variance problems. This problem occurs when significant relationships emerge because the measures come from the same source (i.e., survey) rather than as a result of actual differences. However, the pattern of results found in this study diminishes indications of common method bias. Specifically, each of the three criterion variables demonstrated different relationships with the predictors. This diminishes the likelihood of this problem for the present study. In addition, Spector (1987) indicates that including multiple items greatly reduces this possibility. Because all of the measures in this study include multiple items, the problem of common source variance problems is less of a concern. 
A final limitation of the study was that the research design evaluated crosssectional data. Because of this design, cause-effect and directional inferences are not possible.

Implications for Research and Practice

Several implications can be made from the three hierarchical moderated regression analyses. First, the fact that different relationships and interactions emerged for vigor, dedication, and absorption provides support for the use of three discrete work engagement dimensions.

With regard to the demographic variables, the results of this study revealed the importance in controlling for sample type, organization type, sex, tenure, and age. Controlling for these variables is important for a number of reasons. As mentioned earlier, this study was unable to determine whether organization type accounted for the differential results between the organizational sample and the student sample. Secondly, sex was a significant predictor of dedication, but not the other engagement dimensions. Hence, future research should study reasons why sex might predict vigor, dedication, and absorption differently. Lastly, tenure and age were not significant predictors of vigor, dedication, or absorption; however, tenure and age were related to vigor, dedication, absorption, and affective commitment. Therefore, future studies of engagement and affective commitment should continue to study these demographic variables in order to control for samples that include older and more tenured employees.

Another implication involves the relationship of work resources and the work engagement dimensions. These relationships both support and contradict earlier research 
by Schaufeli and Bakker (2004). Specifically, these findings provide some support for the relationship of work engagement with work resources "more distal from job demands (e.g., skill development, and learning opportunities)" (p. 311). They also provide some empirical support for the motivational component of the Job Demand-Resources (JD-R) model. However, only coworker support for development predicted all three work engagement dimensions. Although resource availability for development significantly predicted dedication, it did not predict vigor or absorption. Furthermore, nonwork support for development and supervisor support for development did not predict vigor, dedication, or absorption.

Given the pattern of results (with the exception of resource availability for development), it appears that the specific work resources relate similarly to all three work engagement dimensions. When work resources pertain to the support one receives for developing work skills, an employee's coworkers are the most important work resource for predicting work engagement. The reason for coworker support for development as a significant predictor of work engagement rather than supervisor support, nonwork support, and resource availability is unclear. Additionally, the non-significant prediction of vigor, dedication, and absorption from supervisor support for development contradicts Schaufeli and Bakker's previous study. Specifically, Schaufeli and Bakker found that supervisor coaching and feedback predicted the three work engagement dimensions. Operationally, there is some overlap in definition between coaching, feedback, and supervisor support for development. However, it should be noted that Schaufeli and Bakker studied a substantially larger sample. Because all of the support for development 
variables had significant correlations with vigor, dedication, and absorption, and their inclusion as a set significantly predicted vigor, dedication, and absorption, there is some evidence for their individual predictive ability. Therefore, future research should be conducted using a larger sample size to test the predictive ability of the support for development variables individually.

A third implication of the study deals with the relationships of work attitudes and work engagement. Support was found for job involvement as a significant predictor of dedication and absorption. These findings replicate those reported in Ford and Poms' (2005) study. The reasons for the non significant results for affective commitment are unclear. The divergent findings of affective commitment and job involvement might indicate that work engagement is better predicted by variables at the individual level (which was the case with job involvement) rather than organizational ones. Future research should include individual, interpersonal, and organizational predictors to account for these differences. In addition, the relationships of affective commitment with work resources and work engagement should be studied with a larger sample size.

Finally, the interactions of optimism with work resources, vigor, and absorption provide some support for the study of personal characteristics with work resources and work engagement. Although the size of the interaction of optimism with work resources and work engagement was quite small, the pattern of results should be noted for future research. Although the moderating role of optimism was supported, the vigor and absorption levels for low work resources were not expected (see Figures 1 and 2). Specifically, when work resources were low, the level of vigor and absorption were lower 
when individuals were high in optimism than when they were low in optimism. This finding runs counter to what Riolli \& Savicki (2003) found when studying the moderating role of optimism with burnout.

It is interesting that optimism had a significant moderating role for vigor and absorption but not for dedication. Perhaps, optimism effects the interaction of physical and cognitive components of work engagement (i.e., vigor and absorption, respectively) rather than dedication. Perhaps, this is because dedication has more emotional connotations than the other two dimensions. These differential relationships need to be studied in future research.

Future research should also study other personal characteristics with work engagement. This research should focus on moderators that will either magnify, accelerate, or buffer the relationship that job demands and job resources have with work engagement. Specifically, evaluating the combined relationships of optimism and pessimism with work resources and work engagement will provide important contributions to the research literature. For example, Macon and Heft's (2005) study demonstrated that pessimism, unlike optimism, accounted for performance ratings above and beyond traditional measures. In addition, the moderating role of pessimism on work resources and burnout exhibited the inverse relationship to that of optimism and the buffering effect of optimism on work resources and burnout in Riolli and Savicki's (2003) study. That is, individuals higher in pessimism reported greater burnout when resources were low than when they were high. Hence, evaluating the role of pessimism with work 
resources and work engagement might help to explain the moderating effect of optimism found in this study.

With regard to organizations, coworkers should support each other's skill development. Organizations need to develop policies and provide resources for employees to develop their skills. Organizations should provide resources to their learning and development departments to provide frequent, empirically developed training sessions. Managers need to provide adequate time for training and encourage their subordinates to attend these training sessions. Although many researchers argue that optimism is a trait, there is a growing body of literature suggesting that optimism can be learned (Hobfoll \& Freedy, 1990; Seligman \& Teasdale, 1978). Therefore, training sessions can focus on increasing employees' optimism.

In conclusion, this study provides support for the study of work resources and work engagement within the positive psychology perspective. Some of the findings question the beneficial role of optimism as a positive personal characteristic with work resources and the three work engagement dimensions. However, in concert, the findings provide some support for the combined relationship of optimism, work resources, and work engagement as contributing qualities for a positive work experience. Therefore, this thesis helps to identify positive work experiences and contributes to the study of a positive psychology. 


\section{References}

Allen, N. J., \& Meyer, J. P. (1990). The measurement and antecedents of affective, continuance and normative commitment to the organization. Journal of Occupational Psychology, 63, 1-18.

Bakker, A. B., Demerouti, E. B., \& Schaufeli, W. B. (2003). Job demands and job Resources as predictors of absence duration and frequency. Journal of Vocational Behavior, 62, 341-356.

Britt, T. W. (1999). Engaging the self in the field: testing the triangle model of responsibility. Personality and Social Psychology Bulletin, 25, 696-706.

Britt, T. W. (2003). Motivational and emotional consequences of self-engagement: Voting in the 2000 U.S. presidential election. Motivation and Emotion, 27, 339358.

Brown, S. P. (1996). A meta-analysis and review of organizational research on job involvement. Psychological Bulletin, 120, 235-255.

Cathcart, D., Jeska, S., Karnas, J., Miller, S. E., Pechacek, J., \& Rheault, L. (2004). Span of control matters. J.O.N.A. Journal of Nursing Administrators, 34, 395-399.

Chang, E. C., Maydeu-Olivares, A., \& D'Zurilla, T. J. (1997). Optimism and pessimism as partially independent constructs: Relationship to positive and negative affectivity and psychological well-being. Personality and Individual Differences, $23,433-440$.

Collins, M. A. (1996). The relation of work stress, hardiness, and burnout among fulltime hospital staff nurses. Journal of Nursing Staff Development, 12(2), 81-85.

Cohen, J., \& Cohen, P. (1983). Applied multiple regression/correlation analysis for the behavioral sciences. Mahwah, New Jersey: Lawrence Erlbaum Associates, Inc.

Csikszentmihalyi, M. (1990). Flow: The psychology of optimal experience. New York: Harper Perennial.

Demerouti, E., Nachreiner, F., Bakker, A. B., \& Schaufeli, W. B. (2001). The job demands-resources model of burnout. Journal of Applied Psychology, 86, 499512. 
Duquette, A., Kerouac, S., Sandhu, B. K., Ducharme, F., \& Saulnier, P. (1995). Psychosocial determinants of burnout in geriatric nursing. International Journal of Nursing Studies, 32, 443-456.

Ford, M. T., \& Poms, L. W. (2005). The role of work engagement in the work-life interface: a study of working students. Paper presented at $20^{\text {th }}$ Annual SIOP conference in L.A.

Friedman, I.A. (2003). Self-efficacy and burnout in teaching: The importance of interpersonal-relations efficacy. Social Psychology of Education, 6, 191-215.

Hackman, J. R., \& Oldham, G. R. (1980). Work Redesign. Reading, MA: AddisonWesley.

Hobfoll, S. E., \& Freedy, J. R. (1990). The availability and effective use of social support. Journal of Social and Clinical Psychology, 9, 91-103.

Kahn, W. A. (1990). Psychological conditions of personal engagement and disengagement at work. Academy of Management Journal, 33, 692-724.

Kahill, S. (1988). Symptoms of professional burnout: A review of the empirical evidence. Canadian Psychology, 29, 284-297.

Kanungo, R. N. (1982). The measurement of job and work involvement. Journal of Applied Psychology, 67, 341-349.

Lawler, E. E., \& Hall, D. T., (1970). Relationship of job characteristics to job involvement, satisfaction, and intrinsic motivation. Journal of Applied Psychology, 54, 305-312.

Lee, R. T., \& Ashforth, B. E. (1996). A meta-analytic examination of the correlates of the three dimensions of job burnout. Journal of Applied Psychology, 81, 123-133.

Lodahl, T. M., \& Kejner, M. (1965). The definition and measurement of job involvement. Journal of Applied Psychology, 49, 24-33.

Macan, T., \& Heft, L. (2005). Optimism and Pessimism: Predictors of success in the workplace? Paper presented at $20^{\text {th }}$ Annual SIOP conference in L.A.

Maslach, C., Schaufeli, W. B., \& Leiter, M. P. (2001). Job burnout. Annual Review of Psychology, 52, 397-422.

Maurer, T, Weiss, M, \& Barbeite, F. (2003). A model of involvement in work-related 
learning and development activity: The effects of individual, situational, motivational and age variables. Journal of Applied Psychology, 88, 707-724.

May, D. R., Gilson, R. L., \& Harter, L. M. (2004). The psychological conditions of meaningfulness, safety, and availability and the engagement of the human spirit at work. Journal of Occupational and Organizational Psychology, 77, 11-37.

Meyer, J. P., Stanley, D. J., Herscovitch, L., \& Topolnytsky, L. (2002). Affective, continuance, and normative commitment to the organization: A meta-analysis of antecedents, correlates, and consequences. Journal of Vocational Behavior, 61, 20-52.

Montgomery, A. J., Peeters, M. C. W., Schaufeli, W. B., \& Den Ouden, M. (2003). Work-home interference among newspaper managers: Its relationship with burnout and engagement. Anxiety, Stress, and Coping, 16, 195-211.

Riolli, L., \& Savicki, V. (2003). Optimism and coping as moderators of the relation between work resources and burnout in information service workers. International Journal of Stress Management, 10, 235-252.

Paulik, K. (2001). Hardiness, optimism, self-confidence, and occupational stress among university teachers. Studia Psychologica, 43, 91-100.

Peterson, C. (2000). The future of optimism. American Psychologist, 55, 44-55.

Rothbard, N. P. (2001). Enriching or depleting? The dynamics of engagement in work and family roles. Administrative Science Quarterly, 46, 655-684.

Schaufeli, W. B, Salanova, M., Gonzalez-Roma, V., \& Bakker, A.B. (2002). The measurement of engagement and burnout: A two sample confirmatory factor analytic approach. Journal of Happiness Studies, 3, 71-92.

Schaufeli, W. B, \& Bakker, A. B. (2004). Job demands, job resources, and their relationship with burnout and engagement: A multi-sample study. Journal of Organizational Behavior, 25, 293-315.

Seligman, M. E., \& Csikszentmihalyi, M. (2000). Positive psychology. American Psychologist, 55, 5-14.

Seligman, E. P., \& Teasdale, J. D. (1978). Learned helplessness in humans: Critique and reformulation, $87,49-74$.

Sonnentag, S. (2003). Recovery, work engagement, and proactive behavior: A new 
look at the interface between nonwork and work. Journal of Applied Psychology, $88,518-528$.

Spector, P. E. (1987). Method Variance as an artifact in self-reported affect and perceptions at work: Myth or significant problem? Journal of Applied Psychology, 72, 438-443.

Tetrick, L. E. \& Farkas, A. J. (1988). A longitudinal examination of the dimensionality and stability of the organizational commitment questionnaire (OCQ). Educational and Psychological Measurement, 48, 723-735.

Tuten, T. L., Neidermeyer, P. E. (2004). Performance, satisfaction and turnover in call centers: The effects of stress and optimism. Journal of Business Research, 57, 2633. 


\section{Footnotes}

${ }^{1}$ Alpha was set to .10 in testing the interactions following Cohen \& Cohen's (1983) guidelines.

${ }^{2}$ Alpha was set to .01 for testing the simple linear regressions following Cohen $\&$ Cohen's (1983) guidelines. 
Appendix: Survey Items

\title{
Vigor
}

When I get up in the morning, I feel like going to work.

At my work, I feel bursting with energy.

At my work, I always persevere, even when things do not go well.

I can continue working for very long periods at a time.

At my job, I am very resilient, mentally.

At my job, I feel strong and vigorous.

\section{Dedication}

To me, my job is challenging.

My job inspires me.

I am enthusiastic about my job.

I am proud of the work that I do.

I find the work that I do full of meaning and purpose.

\author{
Absorption \\ When I am working, I forget everything else around me. \\ Time flies when I am working. \\ I get carried away when I am working. \\ It is difficult to detach myself from my job. \\ I am immersed in my work. \\ I feel happy when I am working intensely.
}

\section{Job Involvement}

The most important things that happen to me involve my present job.

To me, my job is only a small part of who I am. (R)

I am very much involved personally in my job.

I live, eat and breathe my job.

Most of my interests are centered around my job.

I have very strong ties with my present job, which would be very difficult to break.

Usually I feel detached from my job.

Most of my personal life goals are job-oriented.

I consider my job to be very central to my existence.

I like to be absorbed in my job most of the time.

\section{Coworker Support for Development (CW Support)}

My coworkers believe that learning and training activities are important. (1)

My peers/coworkers are supportive of learning activities. (2)

The people I work with participate in training and learning activities. (3) 
My peers at work are supportive of my efforts to improve and develop my career relevant skills. (4)

My subordinates at work are supportive of my efforts to improve my career skills. (5)

People I work with are supportive of my efforts to improve my career skills. (6)

"Customers or Clients" are supportive of my efforts to improve my career skills. (7)

My coworkers encourage me to believe that I can learn and improve at work. (8)

People at work have persuaded me to think that I am capable of improving and

developing my work skills. (9)

\section{Supervisor Support for Development (SV Support)}

My supervisor is supportive of my efforts to improve my work skills. (1)

My supervisor helps me to develop career plans. (2)

My supervisor provides me with a useful performance appraisal. (3)

My supervisor provides me with ongoing feedback. (4)

My supervisor provides adequate time for me to attend training. (5)

My supervisor's behavior facilitates my participation in learning activities. (6)

My supervisor encourages me to participate in activities which promote skill improvement. (7)

My supervisor does not support my participation in learning activities. (8R)

My supervisor has tried to make me believe that I am capable of learning and improving at work. (9)

My supervisor has been a "cheerleader" when it comes to my learning and improving at work. (10)

In his/her own way, my boss tells me that I am able to increase my career skills and learn new things. (11)

\section{Policies/Resource Availability for Development (Resource Availability)}

There are learning and skill development resources available to me through my employer that can help me improve my career skills. (1)

Skill development options or learning materials can be obtained by me that will assist in improving my job/career skills. (2)

There are no effective development options or resources available that can help me improve my career skills. (3R)

The policies and work rules where I am employed make it possible to participate in career related learning and development activities. (4)

Regulations, reward policies and time constraints where I work make it difficult to participate in career-related learning and development activities. (5R)

Our company places much value on employee learning and development activities.

My employer emphasizes employee learning to its employees. (6)

My employer does not have an employee learning orientation. (7R)

\section{Nonwork Support for Development (Nonwork Support)}

Members of my family are supportive of my learning new things and improving career skills. (1) 
Friends outside of work are supportive of my efforts to improve my career skills. (2) People I know "off-the-job" are supportive of my efforts to improve my career skills. (3) People I trust and confide in (friends, family) are supportive of my efforts to improve my career skills. (4)

Individuals I spend time with after work are supportive of my efforts to improve and develop my career-relevant skills. (5)

Friends outside of work have persuaded me to think that I am capable of improving and developing my work skills. (6)

People I trust (family, friends) have discouraged me from believing in my self when it comes to expanding my career skills. (7R)

\section{Affective Commitment}

I would be very happy to spend the rest of my career in this organization.

I really feel as if this organization's problems are my own.

I do not feel like "part of the family" at my organization. (R)

I do not feel "emotionally attached" to this organization. (R)

This organization has a great deal of personal meaning for me.

I do not feel a strong sense of belonging to my organization. (R)

I find that my values and the organization's values are very similar.

Often, I find it difficult to agree with the organization's policies on important matters relating to its employees. (R)

\section{Optimism}

In uncertain times, I usually expect the best.

I always look on the bright side of things.

I'm always optimistic about my future.

When I undertake something new, I expect to succeed.

Where there's a will, there's a way.

In general, things turn out alright in the end. 